\title{
"La verticalidad no es democracia". Notas sobre el nuevo edificio legislativo de Costa Rica
}

\author{
Edgar Pérez Saborío \\ Pedro Monge Fernández
}

Artículo

\begin{abstract}
Resumen
Este artículo es una exploración crítica al proceso en que se materializa el nuevo edificio legislativo en Costa Rica en medio de polémicas, controversias políticas, institucionales y arquitectónicas. Partimos de una aproximación teórica que comprende el edificio como un artefacto socio-técnico con agencias políticas desde las reflexiones de Trevor Pinch, Wiebe Bijker, Langdon Winner y Albena Yaneva; quienes nos permitirán abordar el proceso y el edificio como producto de disputas entre diversas fuerzas sociales y políticas que luchan por inscribir sus intereses, donde, la arquitectura opera como un instrumento técnico que genera disposiciones políticas. Lo anterior desde una aproximación transdisciplinar que posibilita la comprensión de la complejidad de un proceso largo que se bifurcó en múltiples direcciones y se disputó en muchas arenas. Se trabaja con fuentes primarias, como actas legislativas, oficios, resoluciones, propuestas del proyecto, renders, material audiovisual; y fuentes secundarias, como prensa y bibliografía especializada.
\end{abstract}

Palabras clave: Asamblea Legislativa, artefacto socio-técnico, democracia, disposiciones políticas, transdisciplinariedad.

"Verticality is not democracy." Notes on the new legislative building in Costa Rica

\section{Abstract:}

This article is a critical exploration of the process in which the new legislative building in Costa Rica is built in the middle of political, institutional and architectural controversies. We start from a theoretical approaavach that comprehend the building as a sociotechnical artifact with political agencies from the reflections of Trevor Pinch, Wiebe Bijker, Langdon Winner and Albena Yaneva; who will allow us to approach the process and the building as the product of disputes between different social and political forces that struggle to register their interests and where also architecture operates as a technical instrument that generates political dispositions. We do a transdisciplinary approach that allows the comprehension of complexity of a long process that divides itself in multiple directions and is disputed in many arenas. We work with primary sources such as legislative acts, letters, official resolutions, design projects, renders, audiovisual material, and secondary sources as press and specialized bibliography.

Keywords: Congress, socio-technical artifact, democracy, political dispositions, transdisciplinarity. 


\section{Introducción}

n el año 2018 comenzó la construcción de la nueva sede de la Asamblea Legislativa (AL) de Costa Rica. Conforme pasaron los meses, a un costado de la Plaza de la Democracia fue emergiendo un edificio que comenzó a destacar en el paisaje urbano josefino por su altura y peculiar apariencia. El edificio ha sido testigo silente de años convulsos de tensión social y política en la que, al ser oficialmente la sede parlamentaria, tendrá una participación activa, agenciando relaciones políticas y espaciales entre sus inquilinos (diputados, diputadas y personal administrativo), la ciudadanía y el entorno que le circunda. Esta edificación dista mucho de ser ordinaria y es el producto, la materialización, de un largo proceso repleto de inconsistencias técnicas, políticas, y administrativas que ha dado pie a polémicas y controversias manifiestas en el concurso de diseño. A su vez, este proceso se ha acompañado de denuncias de irregularidades, demandas y enfrentamientos institucionales. En estos aspectos radica el interés y la pertinencia académica de investigar sobre este tema.

El punto de partida corresponde a reflexiones teóricas que permiten comprender que un edificio, entendido como un artefacto socio-técnico, es producto de disputas en las cuales grupos sociales relevantes pugnan para inscribir significados específicos a lo largo de su proceso de desarrollo (Trevor Pinch \& Wiebe Bijker, 2013); y cómo esto, posteriormente, se objetiva en un edificio que tiene cualidades inherentemente políticas y capacidad de agencia (Langdon Winner, 2008); y dónde la arquitectura, en tanto que saber y conocimiento técnico, pero también político, tiene un papel central (Albena Yaneva, 2017). Metodológicamente, trabajamos desde un enfoque transdisciplinar en aras de lograr una visión amplia del tema, que posibilite el diálogo entre la arquitectura y la sociología. Operativamente, se emplea el análisis documental para la revisión de fuentes primarias (actas legislativas, oficios, resoluciones institucionales, propuestas del proyecto, renders, material audiovisual), y secundarias (prensa y bibliografía especializada).

El artículo consta de tres apartados: el primero plantea puntualmente el enfoque teórico; el segundo tiene un corte descriptivo y es donde se recorre el proceso de gestación de la sede legislativa desde el 2011 cuando se firma el fideicomiso con el Banco de Costa Rica (BCR), hasta el 2018 cuando el Centro de Investigación y Conservación del Patrimonio Cultural (CICPC) otorga finalmente el permiso de construcción; el tercero explora la política del edificio, para lo cual analiza desde cinco principios (solidez, transparencia, libertad, democracia y raíces) los cambios de diseño realizados por la firma de arquitectura elegida (Javier Salinas Arquitectos), así como la forma en que se proyecta una política en el edificio que finalmente se construyó. El énfasis en el relato descriptivo-cronológico del segundo y comparativo-analítico del tercero, responden al interés particular por comprender puntualmente aspectos específicos para captar la lógica del proceso, los cambios discursivos y recursivos, así como las traducciones arquitectónicas entre el primer y segundo diseño y la forma en que lo anterior se materializa en el espacio construido. Lo mismo se da con las fuentes que se privilegian en cada uno de los aspectos mencionados.

1 Véase "Internalism and externalism" de Laurence Bonjour en "The Oxford Handbook of Epistemology" (2002), para una revisión epistemológica del par internalismo-externalismo.

2 Cuando se alcanza un diseño ampliamente aceptado y empleado.

\section{Un breve contexto teórico}

El planteamiento de Pinch y Bijker (2013) tiene dentro de sus objetivos deconstruir la linealidad técnica y el internalismo ${ }^{1}$ del cambio con que son concebidos los procesos de innovación que transita cualquier aparato para insertarse en una determinada realidad. Dado que en el proceso de desarrollo de los objetos, su historia y relaciones sociales, económicas, políticas o culturales no son visibles a simple vista o uso, son difuminadas o quedan ocultas (por intención o defecto) una vez que este se estabiliza². Una lectura externalista es útil para abordar de forma crítica las condiciones político-económicas de carácter estructural y la fuerza de las relaciones socio-culturales y comerciales que median el proceso y el aparato en disputa, que lo determinan, conforman y se materializan en él. Dos ejemplos de esto son los diferentes modelos de bicicletas que se diseñaron, hasta llegar al "modelo estándar" contemporáneo (Pinch y Bijker, 2013) 
o el desarrollo y evolución del sintetizador de Robert Moog (Pinch \& Trocco, 2004). A partir de esas reflexiones es que vamos a analizar el nuevo edificio de la Asamblea Legislativa como un artefacto socio-técnico que transgrede los pasos habituales en los que se enmarca la materialización de un proyecto arquitectónico (estudios preliminares, etapa de diseño, planos, permisos y construcción).

La reflexión de Winner (2008) es de utilidad para comprender la capacidad que tienen estos artefactos para estructurar de vuelta la sociedad, esto es, de ser productos y reproductores de relaciones sociales, entendidos como condiciones de posibilidad diseñadas para propósitos específicos que trascienden la función práctica inmediata para la que fueron creados. Al mismo tiempo, si bien supone una definición de usos 0 utilidades posibles, no agota la agencia, sino que determina sus márgenes de acción. Este autor resalta la influencia que tienen algunos artefactos tecnológicos en nuestras formas de vida, en tanto que son concebidos y dotados de cualidades políticas producto de negociaciones técnicas que los llevaron a ser así y no de otra manera. Por este motivo, para Winner investigar solamente el proceso de génesis limita mucho el ámbito de lo político y de la política, entendida como "[...] disposiciones de poder y autoridad en asociaciones humanas, así como actividades que tienen lugar dentro de esas disposiciones" (Winner, p. 28).

Lo dicho hasta el momento es útil para investigar un aparato tecnológico (como un televisor o un Smartphone) o una tecnología, pero también un aparato técnico como un edificio, en tanto que son objetos diseñados mediante un conjunto de conocimientos con un alto grado de tecnificación, pero de igual forma atravesados inherentemente por fuerzas sociales, económicas, políticas y culturales, que terminan por conformar sus disposiciones y capacidad política. Esta conexión se vuelve relevante porque "los objetivos humanos son poderosamente transformados a medida que se adaptan a los medios técnicos" (Winner, p 28). Una lógica en la cual la arquitectura, en tanto que saber socialmente útil y disciplina, está inmersa, como ilustramos a continuación.

Winner (2008) indica que la singularidad de los puentes en las autopistas paisajísticas de Long Island (New York) diseñados por Robert Moses ${ }^{3}$ son el resultado de un proyecto diseñado específicamente para operar como mecanismo estructural que posibilita el uso por parte de unos automotores (los automóviles) y unas poblaciones (usualmente población "blanca" de clases "alta" y "media acomodada" poseedora de dichos vehículos) mientras que dificultaba el acceso de otros (los autobuses de 4 metros de altura), medios de transporte habitual de la población afrodescendiente y de clases bajas. Para lograr esto, Moses instruyó para que el diseño de los arcos de los pasos elevados fuera de solamente tres metros; además, impidió que el ferrocarril llegara hasta Jones Beach. Según señala Winner (2008), citando a Caro -biógrafo de Moses- esto se debió a la inclinación clasista y el prejuicio racial contra la población afrodescendiente y latina, especialmente, puertorriqueños. Como afirma este autor "[...] muchas de sus estructuras monumentales de hormigón y acero representan una desigualdad social sistémica, una manera de manejar las relaciones entre las personas que, después de un tiempo, se convierten en una parte más del paisaje" (Winner, p. $30)$. Aunque ya los puentes no logran cumplir en su totalidad todo el espectro de la intencionalidad atribuida a Moses, estos siguen siendo un mecanismo de acceso que condiciona y regula el paso.

3 Véase "The Power Broker. Robert Moses Caro para una revion York" (1975) de Robert A. vida y obra de Robert Moses, así como de sus repercusiones. Para lo referente al tema de las carreteras, véanse los capítulos 37 -One mile $(p$. 850-885)-, 38 -One mile (afterward) (p.885-895)- y 39 -The Highwayman (p. 895-920).

$4 \quad$ Bajo estas premisas, los puentes de Moses, adquieren un sentido analítico y de mayor provecho para el abordaje de la arquitectura desde esta autora un caso aún más provechoso de abordar desde la arquitectura. Para ampliar el caso se basa en el documental producido por Francesco Garutti del Centro Canadiense de Arquitectura "Misleading Innocence: Tracing what a bridge can do", donde aborda y expone de manera más integra estas dimensiones.
Albena Yaneva (2017) sostiene que Winner señala la relación entre infraestructura y política, pero mantiene analíticamente la separación entre estas esferas y por eso no logra llegar más allá. Por ello, recalca la importancia de considerar la intersección entre ambas para una comprensión más compleja de las tecnologías políticas de la arquitectura. En ese sentido, en lugar de interrogarse solamente cómo el diseño se vuelve político, importa descubrir qué hace y cómo se desempeña políticamente 4 . Yaneva propone cinco formas de politizar la arquitectura: desde los objetos, la práctica, los diseños experimentales, el sitio, los espacios públicos urbanos y la ciudad. Se toma como referente el primero de los aspectos para comprender la política de un objeto arquitectónico como el edificio legislativo, en tanto que artefacto socio-técnico. La autora demuestra la condición de "corazón social" que ha ido adquiriendo la idea del atrio a través del tiempo al permitir rápidos e imprevistos encuentros coloquiales, 0 bien, desplegar una agencia que posibilite e invite a una mayor estancia y permanencia. 
5 La autora puntualiza que no escogió un edificio de uso político (como un parlamento o casa presidencial) precisamente para evidenciar con mayor claridad el tipo de relaciones políticas que propicia un espacio que no alberga una institución de esta índole, al menos en el sentido estricto de política.

$6 \quad$ Yaneva (2017) también referencia la capacidad política y espacial del entrecruzamiento de ideas que hace Moussavi con una comparación analítica de la Architectural Association (AA) y la Harvard Graduate School of Design (GDS). Así mismo, menciona los casos del atrio del Laboratorio de investigación Química de la Universidad de Oxford y el atrio del Instituto de Genómica de la Universidad de New Jersey, como espacios que comparten la cualidad mencionada. Otro tanto, a nivel urbano, con el Centro Vontz en la Universidad de Cincinnati y la Janelia Farm en el campo de investigación del Instituto médico Howard Hughes.

$7 \quad$ Entre la avenida Central y la avenida Primera, calles 15 y 17, de la ciudad de San José.

$8 \quad$ Véase los artículos periodísticos El Castillo Azul: Una histórica mansión en cuesta de Moras (La Nación., 3 de mayo, 2015) y ¿No le gusta la nueva Asamblea Legislativa? Descubra entonces las joyas arquitectónicas de los edificios históricos del Congreso (Herrera, 29 de septiembre de 2019) y el libro El Castillo Azul: ícono de un cambio de era (Mora, 2019).

\section{$9 \quad$ No se incluyen el 2020 y el 2021, dado} que son años que distorsionan el promedio para el periodo de referencia, puesto que ya se contempla un aumento para el pago del fideicomiso. El presupuesto en el rubro de alquileres de edificios, locales y terreros para el año 2020 es de $\phi 13.290$ millones -un aumento de $\$ 334$ millones en relación con el 2019; para el año 2021 ese monto asciende a los $\phi 15.600$ millones (proyecto de Ley de Presupuesto 2021 presentada por el $\mathrm{MH}$ a la $\mathrm{AL}$ para su discusión). Además, la migración al nuevo edificio es lenta y se deben seguir arrendando algunos de los inmuebles que se han ocupado hasta el momento.

\section{0 Órdenes sanitarias N CMU-}

AMB-286-2010, N CMU-AMB-287 y el oficio N CMU-AMB-1015-2014 del 25 de septiembre de 2014.

11 Esta afirmación es una verdad a medias: el fideicomiso estipula que una vez concluido el edificio, este será alquilado por la AL durante 14 años y de esa forma se saldará lo adeudado. Por tanto, será un cargo al presupuesto anual de la República, lo que supone "aporte público de capital" y "adquisición de deuda pública" -aunque no se adquiriera deuda pública directamente para su construcción, que es lo que formalmente quieren indicar
La autora pone como ejemplo el atrio del edificio Benzie de la Escuela de Artes de Manchester $^{5}$, donde describe la forma en que la disposición espacial propicia el encuentro, la conexión y agrupación de las personas, lo mismo que el cruce de ideas y conocimiento ${ }^{6}$.

\section{La (no tan) conocida historia}

Este apartado tiene como objeto hacer un acercamiento al proceso en que se gestó el nuevo edificio de la AL desde que se suscribe el contrato del fideicomiso con el Banco de Costa Rica el 27 de diciembre de 2011, hasta el acuerdo de las partes para construir el segundo diseño y se obtiene el permiso del CICPC el 9 septiembre de 2016. De esta manera se trazan líneas y se abre un sendero para avanzar en el conocimiento de las agencias de actores individuales y colectivos y los efectos de estas, que culminan -de manera activa o pasiva, positiva o negativa- por moldear y materializarse en el nuevo edificio de la asamblea Legislativa, entendido como un aparato técnico.

\section{Confluencia inicial de intereses}

La sede de la AL se trasladó a "Cuesta de Moras"7 en 1958 cuando el Palacio Nacional, construido durante la administración de Juan Rafael Mora Porras (1849-1859), fue demolido en el primer mandato de José Figueres Ferrer (1953-1958). A lo largo de estos años la AL ha llegado a expandirse y ocupar 14 edificios diferentes ( 8 de ellos propiedad pública y los restantes alquilados), de los cuales 3 son patrimonio histórico (Casa Rosada, Edificio Sión y el Castillo Azul ${ }^{8}$ ) (Asamblea Legislativa, s.f.). El Ing. Antonio Ayales, Director Ejecutivo de la AL, señala retrospectivamente en el 2020, que era necesario responder a este problema de la atomización espacial, puesto que estas edificaciones no fueron pensadas para tal fin, lo cual acarrea una compleja lógica administrativa y ha implicado constantes restauraciones, readecuaciones y mantenimiento que genera elevados gastos continuos no reembolsables (Hábitat Soluciones, 11 de agosto, 2020). Para el 2012, el rubro de patrimonio suponía un gasto anual que oscila entre los 200 y los 280 millones de colones (Asamblea Legislativa, s.f.). En el periodo 2012-2019, el promedio anual presupuestado para alquiler de edificios, locales y terrenos es de $\phi 754.051 .111$ y para mantenimiento de edificios, oficinas y locales es de $\phi 179.797 .000$ (Diario Oficial La Gaceta, 2011; 2012; 2013; 2014; 2015; 2016; 2017; 2018) $)^{9}$ Posteriormente, uno de los argumentos recurrentes será la urgencia por dar cumplimiento a la sentencia 019782-2014 de la Sala Constitucional (SC) que le ordena resolver el problema estructural de inhabitabilidad, hacinamiento y accesibilidad $^{10}$ (Asamblea Legislativa, s.f.).

Ayales indica que a lo largo de sus 25 años como director ejecutivo se han planteado hasta 8 iniciativas para construir una sede legislativa que no se han realizado por "motivos políticos", de "gustos", de "imposición" o de "limitaciones presupuestarias" (Hábitat Soluciones, 11 de agosto, 2020). Por lo que, para la AL, la figura del fideicomiso con el BCR permitió sortear todos estos elementos, lo mismo que justificar política y públicamente la viabilidad del proyecto de construcción del edificio mediante una forma de financiamiento que, según se argumentó, no representa un aporte público de capital ni adquisición de deuda pública ${ }^{11}$. A su vez, suponía, acorde a la estimación inicial del 2012, un ahorro anual de $\phi 1.495$ millones (Asamblea Legislativa, s.f.) -para el 2020 esa cifra se estima ${ }^{12}$ en $\phi 1.000$ millones $^{13}$ (Ruíz, 19 de septiembre, 2020)-. El documento fue suscrito el 27 de septiembre de 2011 y refrendado -incluyendo la adenda $\mathrm{N}^{\circ} 1$ - por la División de Contratación Administrativa de la Contraloría General de la República (CGR), mediante el oficio Nº 0537 del 24 de enero de 2012 (Acta de la sesión ordinaria N¹46-2016, 29 de noviembre, 2016).

De esta manera surge la figura del fideicomiso y se convierte en uno de los mecanismos que posibilita el proyecto y demarca sus alcances, dado que brinda los parámetros en que se deben llevar a cabo decisiones, acciones, competencias y responsabilidades al establecer un marco económico y legal de determinaciones objetivadas. Lo anterior delimita el proceso y condiciona el hacer futuro de los actores e instituciones que 
entrarán en juego. Visto de manera aislada, la aseveración anterior tiene un carácter de obviedad, pero enfatizar en el fideicomiso tiene sentido con base en los apuntes teóricos del apartado anterior y se ejemplifica a lo largo del capítulo cuando se muestran algunas de sus actuaciones en el marco del proceso, de esa manera se puede percibir su alcance e implicaciones políticas, económicas, legales y arquitectónicas.

En este sentido, los aspectos de mayor importancia para efectos del análisis de este texto son los referidos a los márgenes de confidencialidad en la información asequible y desde donde se toman las decisiones en el marco de un proyecto público financiado con fondos privados, pues, tanto a nivel financiero, como administrativo y arquitectónico, el fideicomiso tiene un papel central. Aunque, en última instancia y con este marco, las decisiones finales, según las competencias específicas, no siempre fueron tomadas unilateralmente desde el fideicomiso, pero sí bajo su tutela.

\section{Construcción y conflicto de enunciados}

El 11 de julio de 2012 se anunció en el periódico La Nación el concurso 01-2012 "Anteproyecto de los edificios de la Asamblea Legislativa". Según Yurica (abril, 2013) desde 1982 no se celebraba un concurso público de diseño en Costa Rica, motivo por el cual, la decisión del BCR y la AL de optar por esta opción en lugar de recurrir a la figura de la contratación administrativa directa, fue un hito en sí mismo. Estas dos instancias, con la asesoría técnica del CFIA, plantearon los requisitos de admisibilidad (entre ellos, haber construido $5000 \mathrm{~m}^{2}$ o más, y edificaciones de cinco pisos o más), los términos de referencia y designaron al jurado responsable de evaluar las propuestas. El jurado estuvo conformado por el Arq. Álvaro Rojas Quirós (presidente del jurado), el Ing. Fernando Ortiz Ramírez (como vicepresidente del jurado y ex presidente del CFIA), el Arq. Carlos Álvarez Guzmán (ex presidente del CFIA y ex presidente del Colegio de Arquitectos), el Arq. Edgar Martín Ovares (Jefe de Unidad de Mantenimiento de la AL), el Ing. Fernando Trejos Dent, la Ing. Tamara Becerra Cotti y el Arq. Germán Samper Gnecco (miembro internacional del jurado) (Acta de la sesión ordinaria N¹46-2016, 29 de noviembre, 2016).

12 Es preciso constatar empíricamente esta afirmación en el largo plazo para conocer la calidad de la inversión pública, contrastando el ahorro proyectado y el real en rubros como alquileres, seguridad, transporte, remodelaciones, limpieza y servicios públicos.

\section{El costo total de la obra y el monto del} fideicomiso han pasado de $\$ 52$ mil millones en 2012 a $\phi 69$ mil millones en 2017 y a $\$ 86000$ millones en 2019. Esto se debe al paso del primer proyecto al segundo y a que el fideicomiso se fondeó en colones (entre el 2012 y el 2020 se ha tenido que ajustar de acuerdo a las oscilaciones del precio del dólar -el tipo de cambio estimado en 2012 fue $\phi 530$ y pasó en 2018 a ф570). (Granados, 1 de febrero, 2019; Asamblea Legislativa, s.f.; Valverde, 8 de octubre de 2019).

\section{En la edición 80 de la Revista Habitar se realiza una reseña de 18 de los anteproyectos presentados. Véase: https://issuu.com/ arquitectoscr/docs/habitar80digital}

15 El CFIA indicó mediante un correo electrónico fechado el 13 de diciembre del 2019 que la dirección ejecutiva no tiene archivos sobre las bases del concurso ni de su calificación. Por otro lado, los arquitectos Álvaro Rojas y Carlos Álvarez (miembros del jurado consultados) señalaron que tampoco poseían copias de dichas rúbricas, mucho menos de las actas del concurso público.
La recepción de propuestas para el concurso inició el 30 de octubre de 2012. El cartel, que tenía un costo de $\$ 200$, fue adquirido por 70 empresas y fueron presentados 23 proyectos $^{14}$ a los que se les asignaron nombres de cantones nacionales para mantener la confidencialidad en el proceso de valoración y votación. El CFIA rescató el carácter abierto y público del concurso, haciendo énfasis en la importancia de que se trabaje en equipos multidisciplinarios y que participen profesionales recién incorporados con otros ya consolidados (La Nación, 21 de mayo de 2013; Hidalgo, 14 de octubre, 2019; Granados, s.f.). Sin embargo, esta visión fue cuestionada, como consta en un artículo anónimo publicado en La Nación, por una persona que adquirió el cartel y se enteró que no podía participar porque no cumplía con los requisitos. Por ese motivo, señaló que había restricciones para profesionales jóvenes, en razón de que era imposible cumplir con lo estipulado. Esto, acorde al Arq. Álvaro Rojas, no fue casual, puesto que los requisitos de admisibilidad "estaban claramente dirigidos a las grandes empresas de arquitectura de Costa Rica, que son muy pocas" (Comunicación Personal, 4 de febrero, 2020). Es decir, a pesar de su apertura formal, había requisitos excluyentes que limitaban la posibilidad de participar en igualdad de condiciones.

Superar el filtro de los requisitos de admisibilidad era la primera etapa del concurso. En la segunda etapa, cada miembro del jurado disponía de 70 puntos para calificar de manera individual los anteproyectos según los rubros de las tablas de evaluación ${ }^{15}$. Los aspectos técnicos evaluados fueron: entorno, ocupación eficiente del terreno, clima y sostenibilidad, función, estructura y forma, carácter, calidad espacial y diseño innovador (Yurica abril 2013). Para acceder a la tercera etapa, el requisito era obtener al menos 60 puntos; en esta se asignaban los 30 puntos restantes, donde se evaluaban los aspectos económicos (15 puntos) y los plazos de elaboración de planos (15 puntos). En la sesión ordinaria $N^{\circ} 07$ del jurado calificador, realizada el 27 de noviembre de 2012, se indica que el anteproyecto Mora obtuvo 67.29 puntos y fue la única que continuó en el proceso y tenía condición de elegible, los demás fueron descalificados ${ }^{16}$. La puntuación 
final fue de 97.29, al obtener la totalidad del puntaje posible en esta tercera etapa (Acta de la sesión extraordinaria $N^{\circ} 155-2013,30$ de enero, 2013).

El 21 de diciembre de 2012, en aras de aclarar dudas sobre la viabilidad del anteproyecto Mora, el BCR envió al oferente el oficio GFC-2012-12-30, donde se le solicitaba, entre otras cuestiones, aclarar si contaría con el permiso del CICPC. El 9 de enero del 2013 los arquitectos Javier Salinas y Karin Nagel (quien se retiraría posteriormente del proyecto) informaron que el CICPC expresó que, en principio, no existían prohibiciones para ejecutar el proyecto (Acta de la sesión ordinaria N¹46-2016, 29 de noviembre, 2016). Pero, en el oficio CPC-069-2013 del 15 de enero de 2013, el CICPC le comunicó al oferente sobre la improbabilidad de otorgar el permiso, por riñas con los "principios de conservación y preservación del patrimonio histórico arquitectónico del país" (Acta de la sesión extraordinaria $N^{\circ} 155-2013,30$ de enero, 2013).

Ante este evento, el BCR recomendó no elegir el proyecto Mora en tanto que no se solucionara favorablemente el tema del permiso antes de la adjudicación. No obstante, dejó esta decisión en potestad de la AL y señaló que, en caso de proceder con la adjudicación y anuncio del proyecto ganador del concurso, el permiso del CICPC era requisito necesario e indispensable para obtener los permisos de construcción, por lo cual era arriesgado seguir adelante. Por otro lado, si se declaraba el concurso desierto, esto suponía iniciar el proceso nuevamente y asumir las consecuencias que tenga en el mandato del fideicomiso en relación con el costo financiero y otros gastos que puedan surgir. Estos hechos fueron conocidos en la sesión extraordinaria N¹55-2013 del Directorio Legislativo, celebrada el 30 de enero de 2013 a raíz del oficio SGF 01 021-13 del fideicomiso. La AL acordó: seguir con el proceso y anunciar al anteproyecto ganador del concurso; que el fideicomiso vigile que la firma escogida cumpla toda disposición que sea obligatoria según la normativa técnica vigente y el ordenamiento jurídico, y; en caso de incumplimiento, el fideicomiso no proceda con la adjudicación final del contrato. La AL tomó esta decisión a pesar de la precaución del BCR y del conocimiento de la consideración negativa preliminar por parte del CICPC (Acta de la sesión extraordinaria $N^{\circ} 155-2013,30$ de enero, 2013).

El 31 de enero de 2013 se anunció en conferencia de prensa que el anteproyecto Mora (imagen 1) era el ganador del concurso. El jurado indicó que la propuesta contenía los siguientes valores: fuerza, claridad, legibilidad, unidad, solidaridad, libertad, tolerancia y justicia ${ }^{17}$, en razón de la forma en que se integra con la ciudad y lograba representar principios democráticos y cívicos. Además de ser una propuesta de "edificio ícono" que cumplía con la aspiración política de una sede legislativa, como enfatizó el Arq. German Samper. Este agregó que uno de sus puntos fuertes radicaba en la tipología del anteproyecto que lograba una solución que lo diferenciaba de las otras propuestas al apostar por un diseño horizontal, un puente, que conectaba los espacios destinados para

$16 \quad$ El jurado tenía la potestad de que la nota mínima de 60 puntos fuera inferior, con lo cual otras propuestas pudieron mantener su condición de elegibles y pasar a la tercera etapa, pero no emitieron consideración al respecto (Acta de la sesión extraordinaria $N^{\circ} 155-2013,30$ de enero, 2013).

\section{Para revisar la descripción que brindan} de cada valor, véase Yurica (abril, 2013, p. 50). En el capítulo siguiente, se reflexionará sobre el tema de las metáforas de cada diseño y la política del edificio, por ese motivo acá solamente se enuncia el tema.

18 Dos anteproyectos fueron descartados por incumplir los requisitos de admisibilidad. Uno de ellos fue "Pérez Zeledón" del consorcio Estudio Saxe, por utilizar un lote frente a la Plaza de la Democracia que no había sido adquirido por el fideicomiso; este espacio también fue empleado por el anteproyecto Mora pero se valoró de manera diferenciada (Hidalgo, E. 2019). la construcción, ubicados en fincas separadas por varias cuadras y con edificaciones patrimoniales en medio. Por estos motivos, lo calificó como un proyecto atrevido pero realizable (Yurica, abril, 2013). Según nos comentó el Arq. Rojas, el Arq. Samper fue de uno de los defensores más entusiastas de la apuesta arquitectónica del proyecto Mora. Y agrega que "Había alguna cosa superior, que era la calidad de ciudad que estaba haciendo este anteproyecto que ganó" (Comunicación Personal, 4 de febrero, 2020). En razón de ello, se argumenta la alta calificación que se le otorgó y la valoración que se hizo.

El veredicto del jurado generó inconformidad entre las firmas participantes del concurso por las dudas sobre los criterios de selección -y su flexibilidad a conveniencia ${ }^{18}$-, críticas de profesionales en arquitectura e ingeniería por la factibilidad de su construcción o su diseño, el costo de la obra, disputas por la legalidad del proyecto ganador y muchas opiniones de la ciudadanía en general. Particularmente hay tres polémicas centrales: la denuncia del Arquitecto Rodrigo Carazo, la alerta formal sobre el riesgo del proyecto del Ing. Gustavo Monge y la negativa del permiso del CICPC. El Arq. Rodrigo Carazo (concursante con el anteproyecto "Upala") presentó una demanda en el Tribunal Contencioso Administrativo el 9 de mayo de 2014 donde señalaba "favoritismo" para el anteproyecto "Mora" por su escogencia a pesar de sobrepasar el monto de la propuesta. En síntesis, indicaba que el diseño ganador infringía la Ley 7555 (Ley de Patrimonio Histórico Arquitectónico) y la Ley 7494 (Ley de Contratación Administrativa). A este 


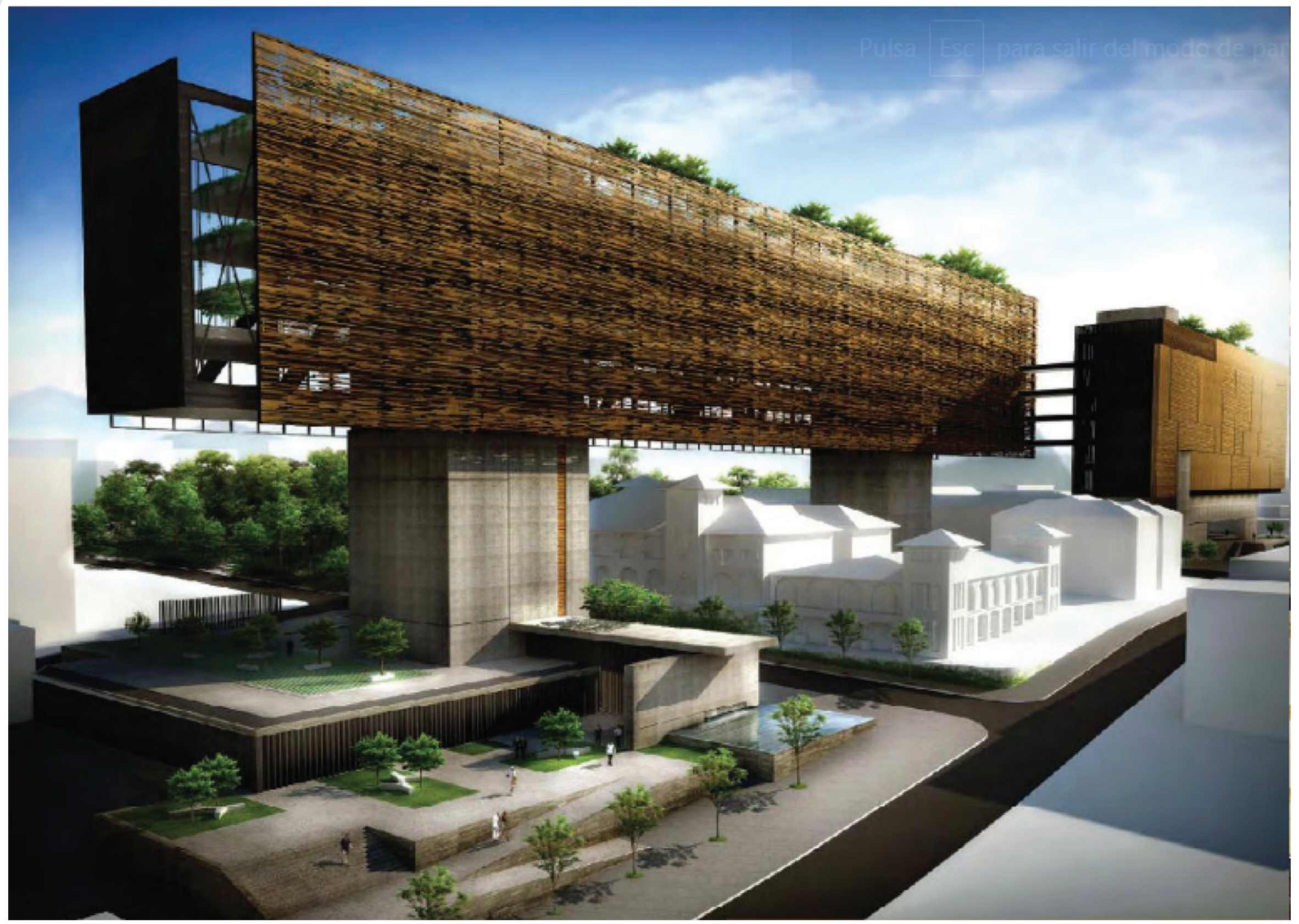

Figura 1. Render del Anteproyecto Mora. Fuente: Yurica (2013). Tomado de: https://issuu. com/arquitectoscr/docs/habitar80digital
19 Con este documento se cierra la polémica con el Ing. Monge que, aunque manifiesta inconformidad por la ligereza de las conclusiones del estudio, se da por satisfecho ante el descargo realizado (Monge, 25 de junio, 2014). respecto, "[...] los representantes del fideicomiso del Banco de Costa Rica indicaron que solo se eliminan ofertas con incumplimientos trascendentales y que el precio de la obra no entra en esta calificación" (Soto, 5 de marzo, 2015). Lo anterior al amparo del principio de eficiencia en la contratación administrativa, tendiente a la conservación del mayor número de ofertas, motivo por el cual se admitió la posibilidad de consultar con el oferente el ajuste a los montos establecidos por el fideicomiso, propuesta que el Arq. Salinas aceptó.

En razón de esta situación, el Ing. Gustavo Monge, encargado del diseño estructural y sismo resistente del anteproyecto y posteriormente asesor del trabajo de la Ing. Marianela Picado y el Ing. Larry Jiménez hasta agosto de 2013 -según señaló-, elevó una alerta formal en una carta del 19 de febrero del 2014 dirigida al Ing. Olman Vargas, Presidente Ejecutivo del CFIA en ese momento. Señaló que los principios y fundamentos estructurales fueron modificados para ajustar el costo de la obra y que esta fuera elegible y que sus objeciones profesionales al respecto habían sido ignoradas; puntualmente, indicó que había "[...] graves diferencias de Estructuración, aplicación de conceptos de Diseño Sismo Resistente y de la norma vigente, hasta manejos administrativos que considero irregulares y que perjudican, no solo a mi persona, sino a la misma transparencia, y por ende a nuestro país" (Comunicación personal, 19 de febrero, 2014). Esta acusación fue rechazada por el Arq. Salinas y apuntó que este no había tenido relación con el contrato de la AL.

Por su parte, el Ing. Julio Cedeño, gerente del Fideicomiso indicó que el diseño estructural fue elaborado por el ingeniero Larry Jiménez y la ingeniera Marianela Picado del Grupo Integra S.A. y enviados a una empresa italiana (Chavarría, 28 de mayo, 2014). Una consecuencia de esta polémica y ante una petición del Directorio de la AL por la negativa del CICPC-MCJ a otorgar el permiso respectivo, fue el Análisis técnico realizado por una comisión de ingenieros estructurales del CFIA en junio de 2014. Donde, grosso modo, la entidad señala que el proyecto era viable y brindó su aval tomando en cuenta estudios sobre el proceso constructivo, cimentaciones y comportamiento del edificio, instalación eléctrica, instalación mecánica y análisis estructural, paisajístico y urbanístico ${ }^{19}$. 
20 El sindicato de trabajadores de la Asamblea Legislativa (ULTRALEG) señaló que la oposición y denuncias del Ing. Carazo, así como la postura negativa del MCJ (con Manuel Obregón como titular) y el CICPC, responden a una serie de vínculos familiares de asesores legales vinculados a estas entidades (Soto, 3 de junio del 2014).

21 El fideicomiso interpuso un recurso de revocatoria con apelación en subsidio contra este oficio el 24 de febrero de 2014; el CICPC respondió mediante CPC 0298-2014 del 28 de febrero de 2014 y mantuvo la resolución de CPC 0235-2014; el 11 de marzo de 2014, mediante Resolución NDM-031-2014, se brindó audiencia al fideicomiso para referirse a CPC-0298-2014 y ampliar la argumentación técnica y jurídica; el fideicomiso respondió con una nota el 24 de marzo de 2014; en la resolución $\mathrm{N}^{\circ} \mathrm{DM}$-044-2014 el MCJ trasladó la nota del Fideicomiso al CICPC, quién respondió en el oficio CPC-0493-2014; mediante la Resolución Administrativa NDM-50-2014 del 31 de marzo de 2014 el MCJ rechazó el recurso de apelación interpuesto por el fideicomiso el 24 de febrero, confirma la resolución del CPC-0235-2014 y cierra el proceso administrativo; el 4 de julio de 2014 el fideicomiso interpuso un recurso extraordinario de revisión a la negativa de permiso en SGF 07252, basado en el Análisis Técnico realizado en junio de 2014 por el CFIA, a solicitud de la AL como consta en el oficio N N Direc. 0269-04-2014 y que le permitió hacer la solicitud de revisión amparado en el artículo 353 de la Ley General de la Administración Pública; lo cual fue referido por MCJ al CICPC y resuelto en CPC-1150-2014 del 10 de julio de 2014.

22 Esta postura es compartida por el Arq. Carlos Laborda (Julio, 2014). Véase: http://www. icomoscr.org/doc/asamblea/ESPECIALISTA_(201407-10)ARQ.CarlosLaborda-contra-informe-CFIA.pdf
A pesar de la polémica que supuso la denuncia del Arq. Carazo y la alerta del Ing. Monge, fue la imposibilidad de obtener el permiso del CICPC para la intervención de los inmuebles denominados "Asamblea Legislativa", "Casa Rosada" y "Castillo Azul", lo que detuvo definitivamente el primer diseño ${ }^{20}$. Ahora bien, como se mencionó previamente, el BCR advirtió a la AL que el CICPC, ante la consulta realizada por el Arq. Salinas el 9 de enero de 2013, indicó preliminarmente en el oficio CPC-069-2013 del 15 de enero de 2013 que, estimaba "improcedente la propuesta sometida a consideración, en virtud de que esta propuesta contraviene y riñe con los principios de conservación y preservación del patrimonio histórico arquitectónico de nuestra nación" (Acta de la sesión ordinaria N¹46-2016, 26 de noviembre, 2016).

En el oficio CPC 0235-2014 del 17 de febrero de 2014, el CICPC resolvió no otorgar el permiso para la construcción de la etapa 2, con base en la Ley 7555 , alegando afectación al entorno de los edificios patrimoniales. Lo que sigue es un periodo de tensión institucional que quedó plasmado en un nutrido intercambio de oficios de apelación y resoluciones entre AL/BCR y el CICPC-MCJ21. La polémica fue cerrada por el MCJ en la Resolución Administrativa NDM-223-2014 del 1 de agosto de 2014, al rechazar por fondo el recurso extraordinario de revisión interpuesto por el fideicomiso contra las resoluciones CPC-0235-2014 y CPC-0298-2014 del CICPC y la DM-502014 del MCJ, al mismo tiempo que confirma en todos sus extremos lo contenido en esta última resolución, agotando la vía administrativa (Resolución NDM-223-2014, 1 de agosto, 2014). El proyecto fue finalmente archivado el 04 de marzo de 2015 y se acuerda diseñar una nueva propuesta arquitectónica y urbana, según consta en la circular N ${ }^{\circ}$ CPC-0308-2015 del MCJ (Circular CPC-0308-2015).

Si bien el objeto central de la disputa fue el permiso para la construcción del edificio, esta llegó mucho más allá e implicó una discusión que, partiendo de la lectura, interpretación y alcance que cada parte hacía de la Ley 7555 -puntualmente, sobre la posible afectación directa, en la edificación patrimonial, e indirecta, en el entorno, que suponía el diseño del proyecto ganador del concurso, la construcción de ciudad y el fundamento filosófico-, puso en duda la autoridad técnica para determinar qué es afectación patrimonial y con base en qué determinarla o cómo hacerlo. Los señalamientos del CICPC sobre afectación directa van desde cuestiones puntuales en el diseño de los planos -que el fideicomiso comunicó que eran errores de dibujo o aspectos rectificados luego de los señalamientos- a temas de fondo sobre la ausencia de estudios técnicos desde los cuales se comprobara que no existiría afectación en las edificaciones patrimoniales durante el proceso constructivo. El fideicomiso presentó como prueba de ello, el Análisis Técnico del CFIA. A lo cual, dentro de muchas otras cuestiones, el CICPC reaccionó indicando que dicho documento dejaba en evidencia la posibilidad de afectación que suponía el proyecto para los edificios patrimoniales. Esto, en la medida de que, por un lado, no lograba demostrar con toda claridad sus argumentos y, por el otro, indica que no encuentra criterios técnicos o condiciones que imposibiliten el desarrollo y ejecución de la obra y daba su aval, a pesar de que manifiesta no tener toda la información disponible para hacerlo22.

La afectación indirecta, referida al entorno, fue el punto más controvertido. El BCR/AL defendía que el edificio legislativo no afectaba el entorno de los edificios patrimoniales, sino, por el contrario, que la obra se integraba perfectamente en el tejido urbano josefino de Cuesta de Moras y sus edificaciones patrimoniales. Además, el inmueble hacía las veces de un escudo protector y de un marco arquitectónico que lograba exaltar el patrimonio como los empaques de las joyas, al ser una respuesta de diseño respetuosa, simple y elegante, al mismo tiempo que moderna y amigable con la ciudad, que se inserta simbióticamente en esta. El CICPC, planteó que el diseño del Arq. Salinas no respetaba la escala de las edificaciones patrimoniales, se excedía con la proporción y no había un intento de integración con los edificios patrimoniales o el entorno al ser una mega estructura que opacaba las edificaciones que estaban a su sombra. Motivo por el cual, las valoraciones del jurado del concurso y del CFIA-que incluso apuntaron que el edificio legislativo podría proteger los edificios patrimoniales del sol y la lluvia- no eran compartidas por la entidad y fueron criticadas. Debido a estos posicionamientos, es que la noción de "técnica" y "lo técnico" fue puesta en entredicho. 
Lo mismo que la lógica de la argumentación, donde la díada BCR/AL reclamaban que se emplearan criterios positivos (calculables, medibles, verificables y estandarizados) que determinaran de manera objetiva la inconstitucionalidad del proyecto; mientras que, sin prescindir de estos el CICPC-MCJ se amparaba en la legislación vigente, convenios internacionales y el criterio experto de la institución en esta materia, para la evaluación respectiva. Lo anterior supuso una disputa por las metáforas y los términos empleados para expresar los argumentos técnicos por los cuales el proyecto era viable, según BCR/AL, o no lo era, acorde al CICPC-MCJ -algunos de estos términos fueron: "escala", "proporcionalidad", "riesgo" y "amenaza", de parte de los primeros, y "joya espacial", "relación simbiótica", "materialidad y contraste", "marco para el patrimonio", acorde a los segundos- y otra por las áreas del saber y las disciplinas del conocimiento implicadas en la construcción de "argumentos técnicos" o enunciados (principalmente ingeniería y arquitectura, con especializaciones y conocimientos específicos en las áreas de interés: historia, arquitectura, antropología, arqueología e ingeniería).

Esta serie de acusaciones en dos vías, señalaban la subjetividad autónoma (en la toma de decisiones y la motivación para una argumentación sin base clara y que respondía a los intereses particulares de cada parte en disputa) y la subjetividad instrumental (en el uso de términos teóricos, jurídicos o técnicos, pero que no refieren a escalas, métricas, valores, fórmulas o cualquier otro medio desde el cual construir indicadores para medir el nivel de cumplimiento o incumplimiento o desde el cual generar un consenso). Esta fue la base para el aumento de fricción en el enfrentamiento institucional que, a pesar del lenguaje formal, muestran cómo la tensión y la prisa por obtener el permiso, hacen que el tono escale y llegue a un punto donde desde el fideicomiso se cuestiona la autoridad del CICPC-MCJ para decidir. Según argumenta esta cantidad, se traslapa e interfiere con la autonomía parlamentaria de la AL, en tanto que Poder de la República, para decidir dónde puede estar su sede y la forma de llevarla a cabo. Por lo cual, la actuación del CICPC-MCJ en defensa del patrimonio arquitectónico e histórico sería inconstitucional y debería abstenerse de actuar pasiva o activamente en este respecto. A lo cual, el CICPC, respondió afirmando que uno de los extremos del mandato constitucional al cual se debe su razón institucional de ser, por una ley aprobada por la propia AL, es precisamente ese, agregando que es la entidad estatal que tiene potestad técnica en la materia.

Todo este tramo del proceso se caracteriza por lo que Pinch (1997) denomina como flexibilidad interpretativa, en referencia a la apertura de diversas lecturas de los grupos sociales de interés sobre lo que el resultado debe-ser, lo mismo que en atinencia a las formas y mecanismos para hacerlo realidad (o poder-ser). Por lo que los enunciados de carácter "técnico" 23 , tanto a nivel arquitectónico, como institucional y legal, entraron en pugna por imponerse a partir de posturas asumidas como indiscutibles (por el peso de los argumentos, la urgencia de llevar a cabo el proyecto o un mandato constitucional). Estos enunciados buscan movilizar relaciones y capacidades políticas que se traducen y se materializan en el edificio. De esta manera constituyen un artefacto socio-técnico con inscripciones, que es resultado de estas disputas (Winner, 2008).

23 El entrecomillado relativiza la idea de que lo técnico sea solamente tal, y que está en una tensión constante con la axiología particular, individual, social o disciplinar. En este sentido aun cuando los actores no lo perciban, los valores hacen las veces de un sombrero que se pone y se quita a conveniencia (ya sea que se haga con mayor o menor discreción).

24 Para la elección del segundo diseño no fue considerada la idea de hacer un concurso de anteproyectos. Esto, entre otros particulares, fue criticado por la Asamblea Ampliada de la Escuela de Arquitectura de la Universidad de Costa (UCR), véase: https://www.ucr.ac.cr/medios/ documentos/2016/pronunciamiento-arquis-ucr.pdf

\section{Hacia una clausura forzada del conflicto}

Luego de que el proyecto adjudicado no obtuviera el permiso del CICPC-MCJ, el Directorio de la Asamblea Legislativa, en tanto que fideicomitente y fideicomisario, decidió en la sesión ordinaria №50-2015 del 24 de marzo de 2015 darle un giro a la gestión y desarrollo para llevarlo adelante ${ }^{24}$ lo que no suponía una adenda al contrato, sino solamente una modificación. Esto implicó cambios como fusionar las etapas 2 y 3 , y construir solamente en un área de aproximadamente $5000 \mathrm{~m} 2$ situados entre avenida central y primera, y calle 15 -acatando la recomendación del CICPC-, y mantener el concepto arquitectónico, la naturaleza del diseño adjudicado y las necesidades derivadas de los términos de referencia que sirvió de base para la adjudicación del proyecto. 
Desde el punto de vista económico, se indica que realizarlo de esta manera generaría ahorro en costos directos (principalmente requisitos de seguridad al laborar en un área sin edificios patrimoniales y funcionariado trabajando) e indirectos (gastos de administración como UAP, gestión financiera, costo de personal institucional, alquileres y porcentaje comisión del BCR). El proyecto se adjudicó de manera directa al Arq. Salinas, argumentando que de esta manera se podía aprovechar la curva de aprendizaje obtenida a lo largo del proceso y se evitaba un incremento en los costos de esta gestión y un aumento en los plazos de ejecución. Lo cual suponía, negociar las sumas adeudadas y la modificación y adecuación de los planos constructivos. Estas gestiones son decididas por el Directorio de AL y comunicadas al fideicomiso para su ejecución a la mayor brevedad posible (Sesión ordinaria N050-2015, 24 de marzo, 2015).

Debido a que el 5 de junio de 2013, luego de declarar al ganador del concurso y adjudicar el proyecto, se firmó un contrato por servicios profesionales con el arquitecto Salinas, este presentó al BCR una gestión reclamando que se le adeudan diferentes extremos por concepto de honorarios del diseño de planos, ampliación de las obras y daños y perjuicios, etc., que ascienden a la suma de $\$ 1.448 .197$. Por este motivo, y para evitar el riesgo de un litigio que nuevamente atrasara el avance del proyecto, el Directorio Legislativo accedió a negociar con el arquitecto. Además, aclaró que que ello no suponía aceptar las responsabilidades o un incumplimiento del contrato anterior, por ello se suscribió un acuerdo con el Arq. Salinas.

En el acta № 57-2015 del Directorio legislativo del 27 de abril de 2015 se aprueba el acuerdo de transacción con el Arq. Salinas, con los siguientes términos: cancelar la suma de US $\$ 825.000$ al Arq. Salinas por concepto de cancelación de honorarios y en forma parcial un reconocimiento de tiempos caídos y contrato, como suma total que cierra la disputa a este respecto y con lo que se salda lo adeudado por el primer proyecto. Contra el pago de este monto ${ }^{25}$, las partes manifiestan conformidad plena y se relevan de tomar cualquier acción civil, penal, comercial o extra judicial a este respecto, por actos pasados o futuros. A partir de esto, el 28 de abril y el 1 de julio del 2015 se firmaron, respectivamente, las Adenda №1 y №2 al contrato 01-2013 (Sesión extraordinaria $N^{0}$ 57-2015, 27 de abril, 2015).

No obstante, en la sesión ordinaria del Directorio Legislativo del 29 de noviembre de 2016 se conoció el oficio No. 12888 de la CGR, fechado el 4 de octubre de 2016, que señala la ilegalidad de los pagos realizados al Arq. Salinas por concepto de los honorarios profesionales adeudados que este reclamó y fueron otorgados como parte del acuerdo señalado previamente. Esto, en razón de que dichos honorarios debían pagarse solo una vez que el contratista hubiese obtenido todos los permisos, como estipula la cláusula 7.3 (El contratista asume el riesgo de obtener los respectivos permisos que se requieren para la obra) del contrato 01-2013, de igual manera que según las cláusulas $2.4,2.6$ y 2.7 de las bases del concurso de anteproyectos, donde se especificaba que el diseño debía cumplir con la normativa específica de la Ley 7555. El monto del $60 \%$ cuyo pago cuestiona la CGR corresponde aproximadamente a $\$ 698.000$.

Por ese motivo, la CGR señala que el acuerdo de la sesión extraordinaria 57-2015 referido anteriormente, con respecto al pago de dichos honorarios, carece de motivo conforme a lo dispuesto en los artículos 133 y 136 de la Ley 6227 Ley General de Administración Pública. Por lo tanto, el hecho de que la AL asumiera el costo económico (aunque no aceptara la responsabilidad derivada) implica una lesión a los fondos públicos y esto no debió realizarse de esta manera. Por este motivo, se suscribió un "Convenio de Consignación" donde el Arq. Salinas aceptó -bajo protesta, puesto que no está de acuerdo en que este cobro sea correcto (Ramírez, 1 de noviembre, 2016)que se le retuvieran, como medida cautelar, $\$ 25.000$ mensuales de los pagos producto de la inspección, hasta completar el monto señalado. Además, la CGR señaló que

25 Menos la deducción de dos facturas, una por $\$ 247.200$ al señor Jaime Ventura y otra por $\$ 365.250$ al Banco LAFISE. era necesaria la declaratoria de lesividad parcial para eliminar la lesión económica y reequilibrar la relación contractual renegociada. Lo cual fue suscrito por el Directorio Legislativo (Sesión ordinaria № 146-2016, 29 de noviembre, 2016).

Posterior al acuerdo mencionado y al margen de la polémica de los pagos, el 8 de septiembre de 2015, se hizo una presentación formal del anteproyecto del nuevo edificio legislativo (figura 2), donde participaron Sylvie Durán Salvatierra, titular del MCJ en ese 
momento, y William Monge Quesada, director del CICPC, quienes manifestaron que no tenían objeciones al anteproyecto presentado. En razón de ello, en el oficio CPC-12592016, el CICPC otorgó el permiso de construcción respectivo, al que se le adicionó una aclaración en el oficio CPC-1473-2016, a petición de Mario Barrenechea Coto, en ese momento Gerente General del BCR. Esto se hizo para explicitar que la obra no afecta negativamente ni el conjunto patrimonial conocido como Asamblea Legislativa, Casa Rosada, Castillo Azul, Antiguo Colegio de Sión y Museo Nacional ni su entorno. Lo anterior respondió, en parte, a un recurso de revocatoria presentado al CICPC el 24 de mayo de 2016 por parte de ICOMOS, posterior a que el 04 de marzo de 2016 se resolviera favorablemente el formulario de Zonas de Control Espacial Municipal No. 015-2016, donde se consignaba que el nuevo proyecto "No afecta edificio con valor arquitectónico". Dicho recurso de revocatoria fue hallado sin lugar en la Resolución №. DM-177-2016 y el proceso siguió adelante (Resolución N DM-177-2016, 4 de agosto, 2016).

Figura 2. Render Vista SO del segundo diseño para el edificio legislativo.

Fuente: Asamblea Legislativa, Documentos de Consultas, Renders, 04 Vista SO. Tomado de: http://www.asamblea.go.cr/ga/Proyectos $\% 20$ Sede\%20Legislativa/2-Proyecto/Renders/04\%20 Vista\%20SO.jpg

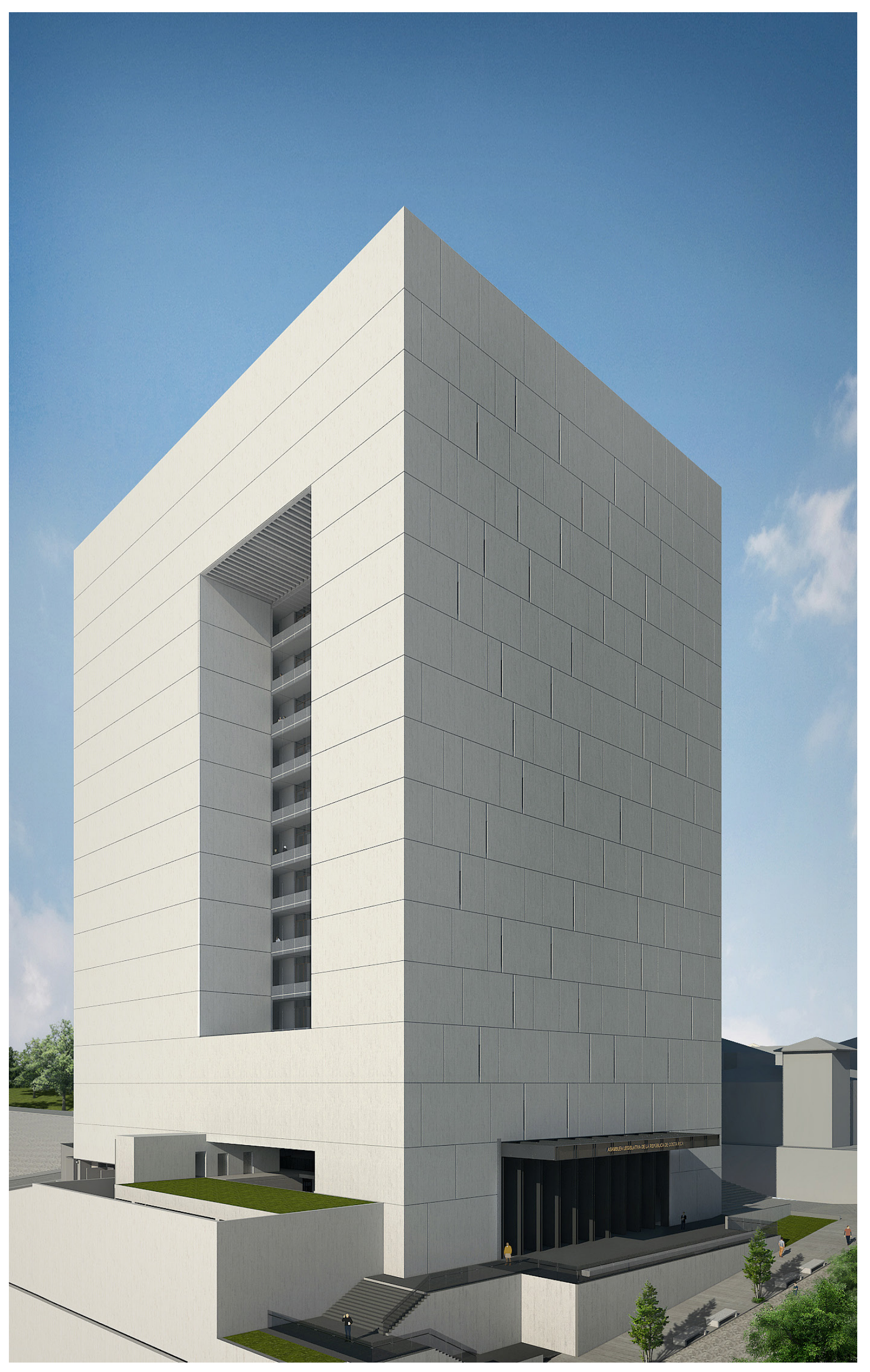


Es así como el convenio de pagos, que deriva en una "solución tramitable", se dispone aquí como un mecanismo de clausura retórico (Pinch y Bijker, 2013) donde, al estabilizarse un aparato tecnológico cesan los problemas de su proceso, lo que no supone que se terminen las controversias completamente, sino que los grupos sociales relevantes consideren resuelto el problema. De esta manera la problemática central de la que surgió la disputa, y las polémicas y controversias que emergieron en el proceso de buscar una solución, no han sido resueltas, pero se presentan como si lo hubieran sido: tanto la AL, como el BCR y el arquitecto Salinas están satisfechos -en acuerdo a sus respectivos intereses (tener una nueva sede, ejecutar el fideicomiso y obtener el rédito económico)- con el cierre de las problemáticas. De esta manera, las condiciones de flexibilidad interpretativa sobre la solución pertinente ante la adversidad técnica, "desaparecen". Sin embargo, no se cerró a cabalidad la discusión del tema patrimonial como quedó en evidencia con el recurso presentado por ICOMOS, así como tampoco se cerraron las controversias arquitectónicas, financieras, sociales y políticas, e incluso se abrieron nuevas a partir de que se conoció públicamente el nuevo diseño del Arq. Salinas.

El mejor ejemplo de lo anterior es que, en medio de una multitud de comentarios y valoraciones negativas del diseño, la construcción inició el 7 de marzo de 2018 en un acto oficial, donde se depositó en sus cimientos una cápsula que contenía el contrato con el fideicomiso y de financiamiento, la orden de inicio de obras, la Constitución Política, la Ley Fundamental del Estado de 1825, el Pabellón Nacional y una Biblia (Alfaro, 7 de marzo, 2018). Por lo demás, el edificio tiene fecha de entrega para octubre de 2020.

\section{Las disposiciones políticas del artefacto}

A la luz de lo expuesto en el apartado anterior es posible entrever que gran parte de las discusiones giran en torno a criterios de carácter técnico que, asumidos de la manera en que se hicieron, invisibilizan la complejidad de las disposiciones políticas que los diversos actores sociales buscan inscribir en el inmueble. Si bien la exposición del proceso ayuda a superar el "determinismo tecnológico ingenuo" con el que se suele concebir una obra arquitectónica, es necesario aún explicitar las características particulares de los objetos técnicos y el significado que estas adquieren para situar la política que promueve el artefacto hacia su contexto social y urbano más amplio. La "carta blanca" que abre el viraje forzoso del primer al segundo proyecto, dará cuenta de las intenciones que lograron incorporarse en este. $Y$ que, finalmente con su materialización, agenciaron una serie de disposiciones políticas de vuelta hacia la ciudadanía que esbozaremos a modo de hipótesis.

\section{Transformación discursiva}

Del primer al segundo proyecto hay cambios significativos en las soluciones arquitectónicas y sus discursos asociados, los cuales buscan sustentar, bajo criterios de carácter "técnico", algunas connotaciones políticas particulares que pretenden ser representadas y transmitidas por la firma proyectista y que no se limitan solamente a los requerimientos de la $\mathrm{AL}$, el terreno donde se deben construir o el costo de la obra. En la propuesta original del Arq. Salinas y Asociados se parte de una concepción idealizada (Molina, 2005; Jiménez, 2002) e inequívoca del ser costarricense. El slogan "PatrióTICO" refiere al

[...] ciudadano de Costa Rica quien conoce y aprecia sus cimientos filosóficos e históricos, practica civismo con honesta disposición, no señala más de lo que propone, sabe que el medio ambiente debe ser atesorado y cree en lo más profundo de su ser que el futuro debe ser caracterizado por un esfuerzo conjunto y progreso con conciencia. (La República, 2013, s.p.).

Esta idea se reafirma en un audiovisual donde se presenta el primer proyecto mediante esquemas animados que bosquejan la inclinación conceptual del proyecto y se articulan desde dos sentencias cortas y directas, a partir de las cuales se hace un señalamiento 
Figura 3. Democracia vertical según el primer diseño de Javier Salinas.

Fuente: La República, 31 de enero 2013. Tomado de: https://www.youtube.com/watch?v=MoMPfW5EKo

Figura 4. Democracia horizontal según el primer $>$ diseño de Javier Salinas. Fuente: La República, 31 de enero 2013. Tomado de: https://www. youtube.com/watch?v=M-oMPfW5EKo claro de la tipología del edificio y de su significado: "La verticalidad no es democracia" (figura 3) y "la democracia es horizontal" (figura 4). Esta representación tan sencilla marca un punto de inflexión que la separa de las otras propuestas concursantes que presentan soluciones arquitectónicas verticales (más allá de sus diseños particulares), y que por ende, serían "no-democráticas". Con lo cual, la representación y objetivación material de los principios asumidos como propios de lo costarricense hizo que ganara el concurso. Con esto se logró una continuidad entre la representación conceptual y gráfica y la promesa de un edificio legislativo ícono (Yurica, abril, 2013).

A lo anterior se le suman valores e ideas genéricas con los que amplios grupos de personas pueden estar de acuerdo, e intenta incluirlos con un repertorio de imágenes fugaces al discurso del proyecto, sin mostrar ninguna relación técnica de por medio, dejando ver la aleatoriedad con que son asignados estos valores a un proyecto arquitectónico (La República, 31 de enero 2013). Por ejemplo, ideas abstractas como "Un edificio de la gente", o bien términos como transparencia, ciudadanía, democracia, progreso, futuro y sostenibilidad son interpuestas sin mayor criterio, explicación 0 correlato claro, sobre cómo la obra muestra y refleja dichas ideas o porqué esta sería una digna representación.

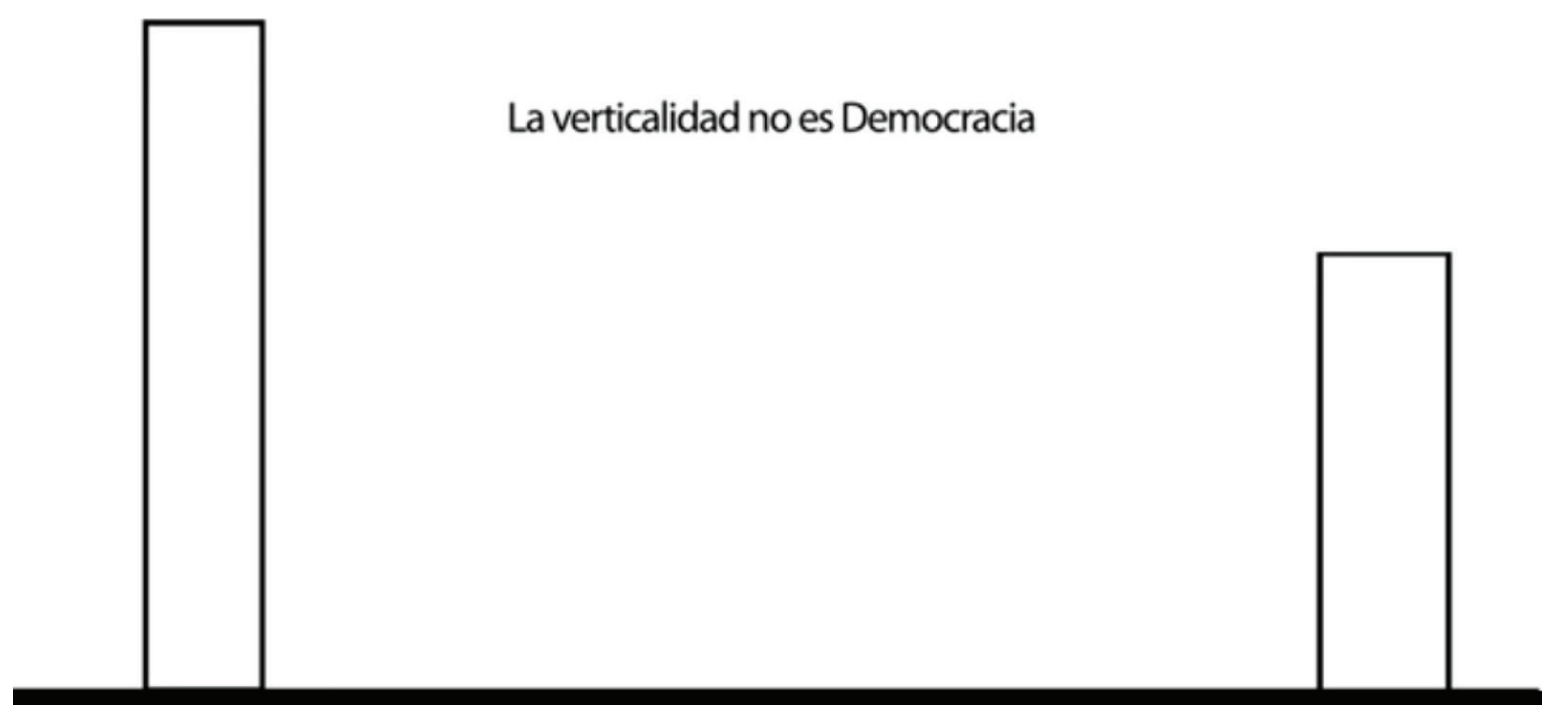

La Democracia es horizontal
Figura 5. Síntesis conceptual de la primera propuesta e imagen inicial del nuevo anterproyecto. Fuente: Asamblea Legislativa, s.f. Tomado de: http://www.asamblea.go.cr/ga/SitePages/Proyecto_ Edificio_AsambleaLegislativa.aspx

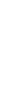


En la lámina de "concepto", tan solo algunas páginas después de rescatar el esquema horizontal, se muestran ahora dos volúmenes verticales en un diagrama en corte (ver figura 6), si bien el esquema no asemeja la forma total del edificio tal cual es percibida en la realidad, este sí evidencia el proceso inverso al originalmente propuesto. El Arq. Luis Monge hace alusión a esto afirmando que el edificio se vuelve a convertir en una torre al igual que las anteriores 23 propuestas, dado que era imposible solucionar de otra manera el programa "leonino" que se solicita desde la AL y considerando el terreno que se tenía a disposición. (Asamblea Legislativa de Costa Rica, 7 de octubre, 2019). De modo tal que el resultado de la salida acordada por el Directorio Legislativo con el Arq. Salinas, termina socavando el propósito que pretendía la realización del concurso y la validación de sus pares, tanto desde su representación formal (al tender ahora hacia la verticalidad), así como en la jerarquía vertical de dicha decisión político-técnica.

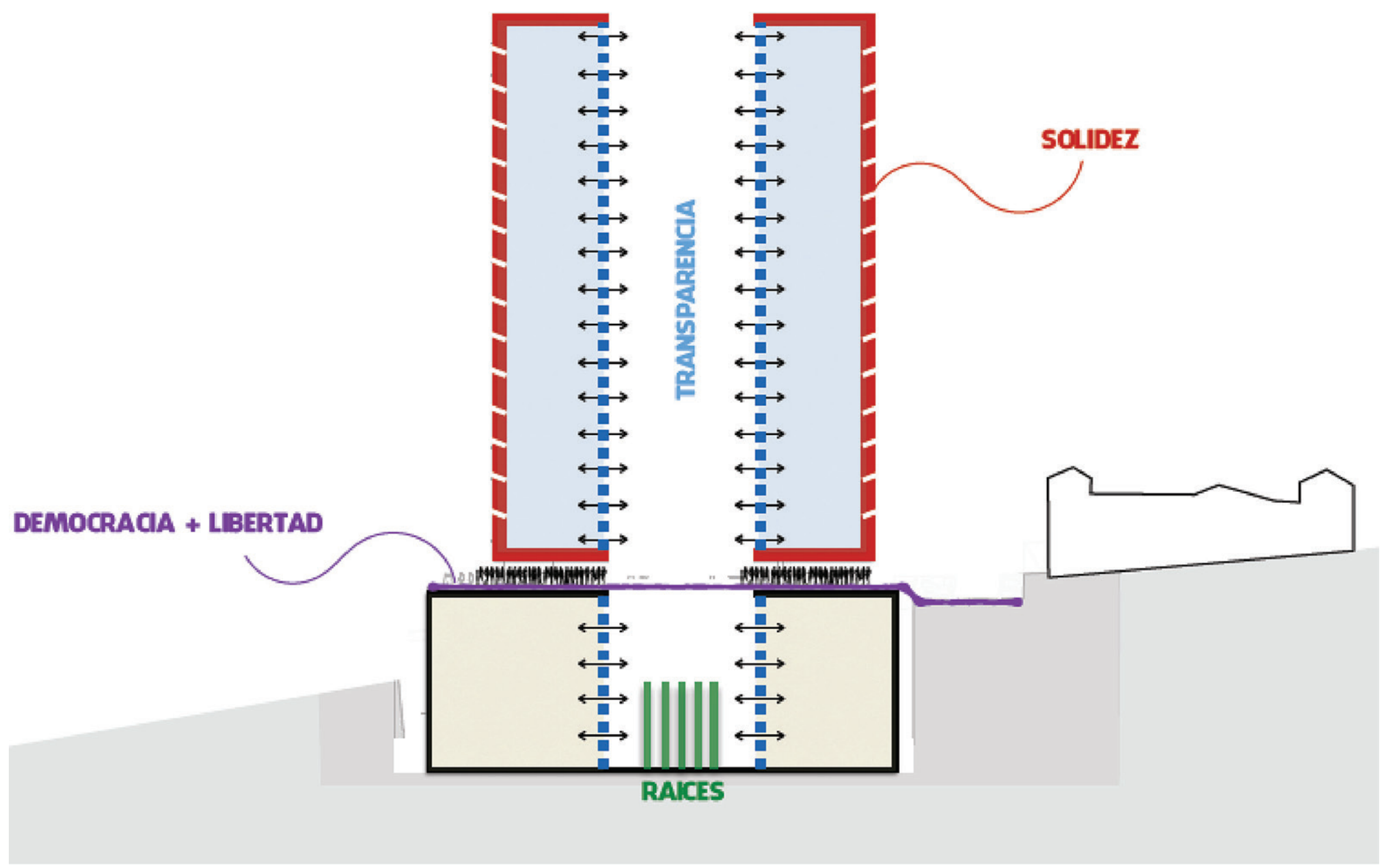

Figura 6. Diagrama conceptual en corte. Fuente: Asamblea Legislativa, s.f. Tomado de: http://www.asamblea.go.cr/ga/SitePages/Proyecto_ Edificio_Asamblea_Legislativa.aspx

Figura 7. Valores conceptuales de segunda propuesta.

Fuente: Asamblea Legislativa, s.f. Tomado de: http://www.asamblea.go.cr/ga/SitePages/Proyecto_ Edificio_Asamblea_Legislativa.aspx

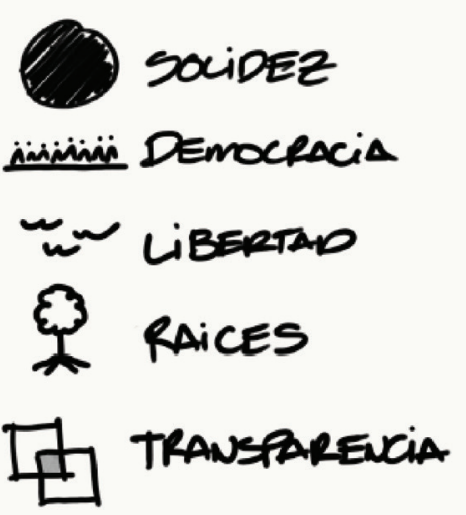

Para la presentación del nuevo anteproyecto se omiten las anteriores valoraciones $y$, en lugar de ello, se anuncian cinco palabras con cinco diagramas para generar un nuevo "concepto" (figura 7). Este, tal como se replica en diversas entrevistas (Asamblea Legislativa de Costa Rica, 7 de octubre, 2019; Hábitat Soluciones, 11 de agosto, 2020), resulta todo el soporte argumentativo para el nuevo acto proyectivo.

Tres de estas palabras: "democracia", "libertad" y "transparencia", buscan dar continuidad al proyecto dada la solicitud expresa de la AL de mantener la "naturaleza del diseño adjudicado" (Directorio Legislativo, Asamblea Legislativa, 27 de abril, 2015), mientras que los diseñadores adjuntan otras nuevas ("raíces" y "solidez") ante los nuevos rasgos distintivos y la notoria predominancia formal de sus cerramientos hacia la ciudadanía. Si bien la solidez no fue explícita como un rasgo importante en la propuesta del concurso, una de sus fachadas (la menos extensa con solo el $20 \%$ del área total de las fachadas Norte-Sur), si posee el vestigio que llegó a ser la base del nuevo diseño (ver el volumen derecho de la figura 8). La decisión sobre la "solidez" de las fachadas se pretende fundamentar no solo sobre sus connotaciones y representaciones políticas, sino que se argumenta desde los criterios técnicos de la adaptación climatológica. 
Figura 8. Render vista aérea fachada Norte. Fuente: Nagel Arquitectos. Tomado de: http:// www.nagelcr.com/web/projects/propuestaganadora-asamblea-legislativa/asamblealegislativa/?lang=en

Figura 9. Render desde calle 17 de las fachadas Sur del primer proyecto.

Fuente: Nagel Arquitectos. Tomado de: http://www. nagelcr.com/web/projects/propuesta-ganadoraasamblea-legislativa/asamblea-legislativa/?lang=en
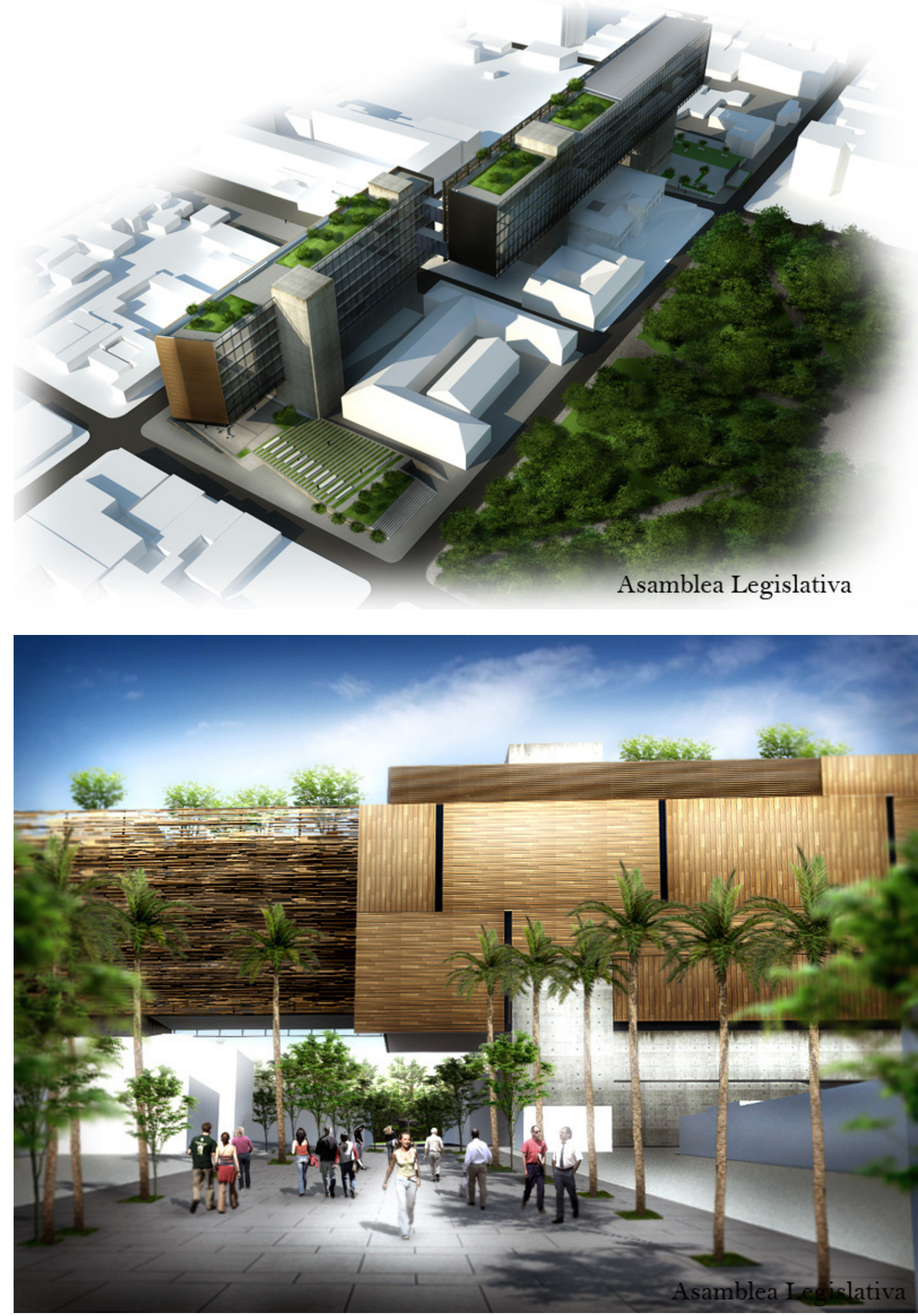

Acá hubo un cambio importante en cuanto a estos, ya que, en su primera versión, las dos fachadas sur efectivamente poseen un tratamiento más cerrado debido a la alta incidencia solar del trópico austral (con lo que se busca dar sombra y atenuar el soleamiento directo), sin embargo, toda la fachada norte, que mira hacia el Parque Nacional, tiene una incidencia de luz indirecta que permite abrir la fachada en vidrio. Esta característica fue empleada por los autores para connotar la transparencia del sistema político costarricense (ver figura 8).

Resulta irónico, cómo en la segunda propuesta, el proyecto se reviste de una coraza de concreto de cara hacia la ciudad en sus 4 direcciones, y tan solo se retoman las pequeñas aperturas verticales de la fachada más cerrada de la propuesta original (figura 9). El tratamiento bioclimático diferenciado que se daba a la materialidad externa del edificio, pasa ahora a unificarse a una sola y se cambia por el criterio técnico de la conducción térmica del concreto, la cual proponen, evita la fuerte radiación solar del trópico (a pesar de la diversidad de soluciones que proponían anteriormente). La frase "no es un edificio sin ventanas" (figura 10), busca solventar el conflicto sobre la apertura, en un edificio donde es posible mirar desde adentro pero no ser visto por las personas al nivel de la calle. Se emplea el mismo tipo de protección de las aspilleras, propia de los antiguos bastiones defensivos (figura 11). 
Figura 10. Render de las "ventanas" del edificio "No es un edificio sin ventanas". Asamblea Legislativa, s.f.

Tomado de: http://www.asamblea.go.cr/ga/ SitePages/Proyecto_Edificio_Asamblea_ Legislativa.aspx
La mencionada transparencia se relega ahora únicamente a su interior. Hay serios cuestionamientos que se le podrían realizar al surgimiento de tan radicales cambios desde su proceso, sin embargo, las evidencias en este caso solo dan para soportar la afirmación de que los criterios técnicos sobre la "protección bioclimática" son empleados como justificación de las implicaciones que tiene esta fachada hacia otras muy diversas áreas (visibilidad, paisaje, estética) e incluso como argumento para encubrir la agencia política defensiva que tiene hacia la ciudadanía.

Ante estas pruebas materiales, la siguiente argumentación de Salinas toma otra acepción:

¿¿Qué es lo que hacemos? Primero que todo manejamos la solidez por ser la primera democracia de Latinoamérica, la más antigua de todas. $Y$ esa solidez lo que hace es, pretende no solo generarse como un elemento hito, sino que autoprotegerte, se autoprotege del clima. Estamos en el trópico y lo que hacemos es autoprotegernos todo el día del asoleamiento ¿y que evitamos? Evitamos que el calor se nos meta al edificio." (Hábitat Soluciones, 11 de agosto, 2020).
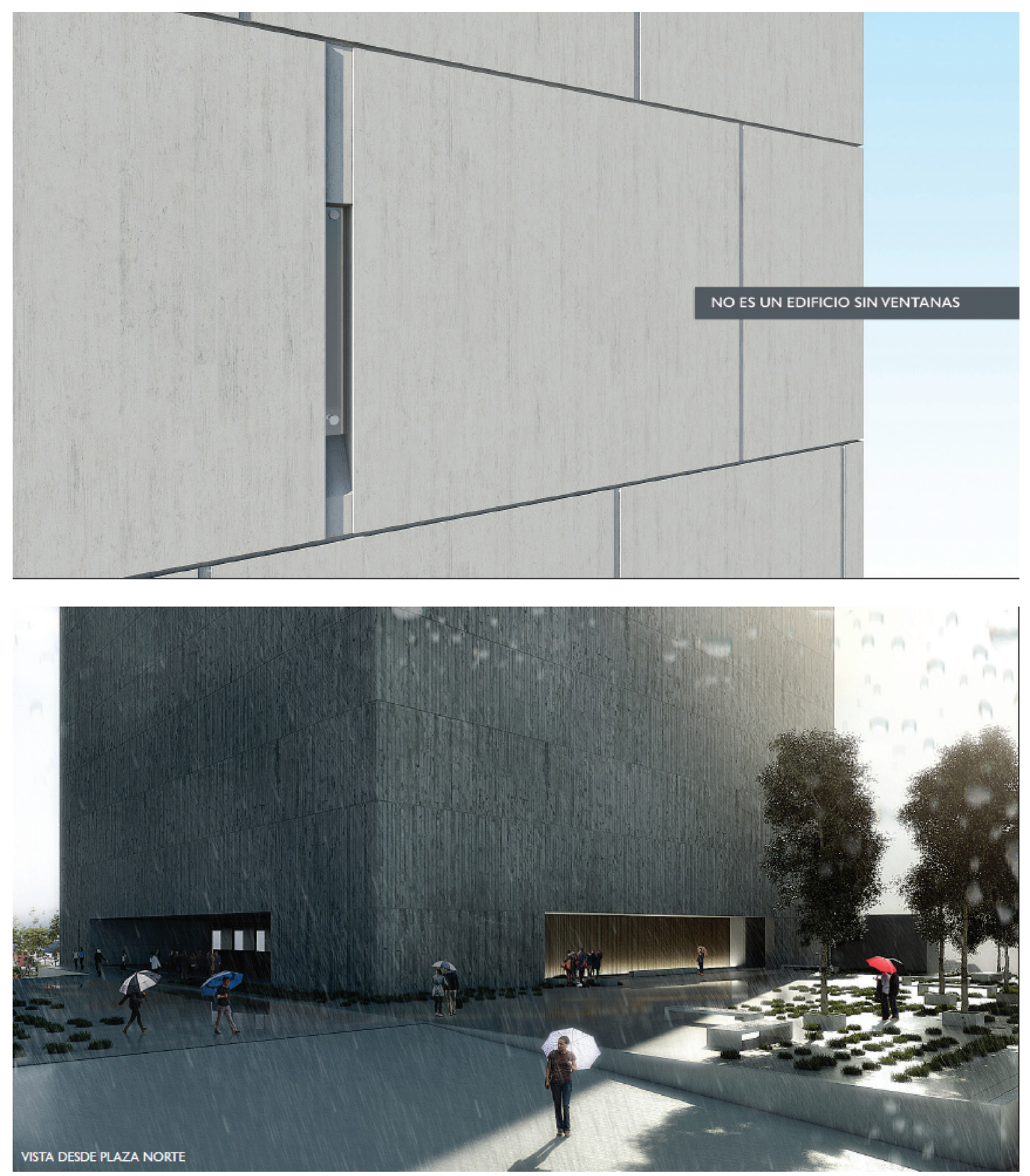

No solo la solidez y la transparencia van a tener vuelcos importantes en el giro hacia el segundo proyecto, muchos otros sufrieron una transformación discursiva radical que va a intentar balancearse entre la continuidad conceptual y un intento por modelar las nuevas connotaciones políticas que se desprenden de nuevos requerimientos. Ejemplo de ello van a ser las adjetivaciones sobre la "libertad" y "democracia", las cuales en el primer proyecto fueron elogiadas por el jurado, quienes afirmaban que "Las distribuciones espaciales están planteadas dentro del concepto de planta libre y flexible. Esto no solo sugiere la simbolización de este valor cívico, sino además facilidad de funcionamiento y adaptación a cambios futuros, incluso a correcciones en la propuesta." (Yurica, abril, 2013, p 50). Sin embargo, en la nueva propuesta las distribuciones de las oficinas se encuentran definidas y confinadas a un programa concreto ${ }^{26}$ (ver figura 12). Ya sea por un cambio argumentativo de la firma proyectista o bien, por solicitud expresa de los usuarios o del fideicomiso, en ambos casos se evidencian las inconsistencias 
del proceso, la discrepancia con los criterios que validaba y privilegiaba el jurado en contraste con lo que termina siendo el proyecto a partir de sus procesos internos.

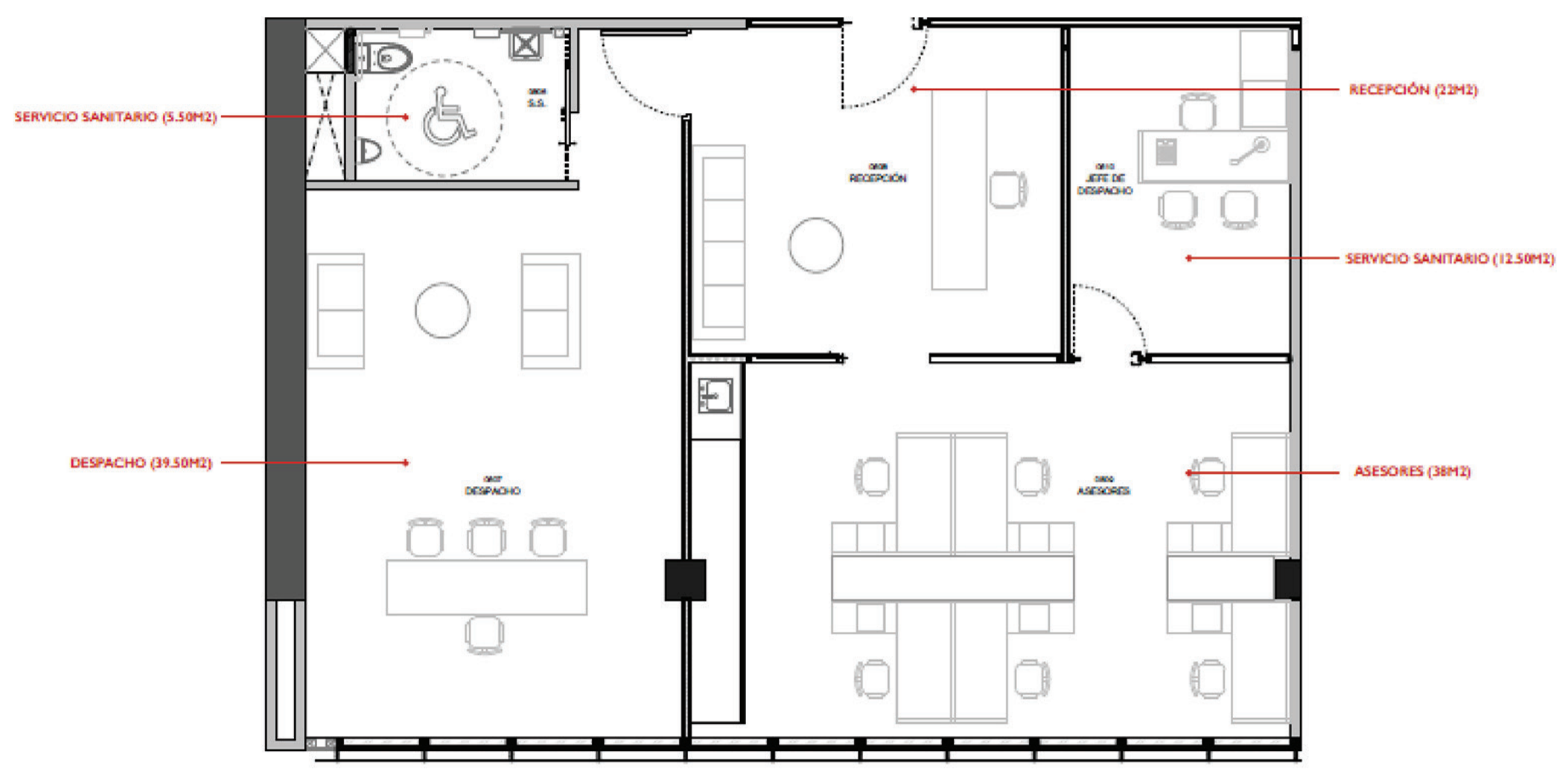

Figura 12. Planta arquitectónica de un módulo de oficinas para las diputaciones. Asamblea Legislativa, s.f.

Tomado de: http://www.asamblea.go.cr/ga/ SitePages/Proyecto_Edificio_Asamblea_ Legislativa.aspx
Figura 13. Esquema en corte de la primera propuesta, ciudadanía sosteniendo los volúmenes. Fuente: La República, 31 de enero 2013. Tomado de: https://www.youtube.com/ watch?v=M-oMPfW5EKo

Figura 14. Esquema en corte de la segunda propuesta, ciudadanía sosteniendo los volúmenes. Asamblea Legislativa, s.f.

Tomado de: http://www.asamblea.go.cr/ga/ SitePages/Proyecto_Edificio_Asamblea_ Legislativa.aspx

28 Este discurso será desarrollado en repetidas ocasiones por los promotores del proyecto. Véase por ejemplo en Asamblea Legislativa de Costa Rica (7 de octubre, 2019) minuto 5:23.

\section{El entrecomillado responde a que nos} proponemos cuestionar en el siguiente capítulo este tipo de recursos como aproximaciones arquitectónicas muy limitadas e incluso hasta autoritarias en tanto se tienen que entender de la manera en que se presenta.
Al no contar más con la anterior traducción material, las cualidades de la "libertad" y "democracia" se transforman hacia la segunda propuesta a un discurso que alude a la "libre" circulación en el nivel urbano ${ }^{27}$, en relación con una idea de participación cívica donde la ciudadanía "sostiene" y participa del edificio 28 (figura 14). El Arq. Salinas busca conectar esta idea del primer al segundo diseño a pesar de la inversión de los volúmenes (en el primer caso horizontales, y en la segunda verticales), ocasionando un cambio abrupto de escala de la ciudadanía en relación a la nueva disposición del inmueble (ver figuras 13 y 14), en el primer caso guardando consistencia con el argumento de la democracia y la horizontalidad (e incluso teniendo sentido con principios físicos básicos como fuerza/área), en el segundo volviéndose casi una condición aplastante. En todo caso, de allí deviene otro criterio simbólico que sitúa una representación política mediante "recursos arquitectónicos" 29.
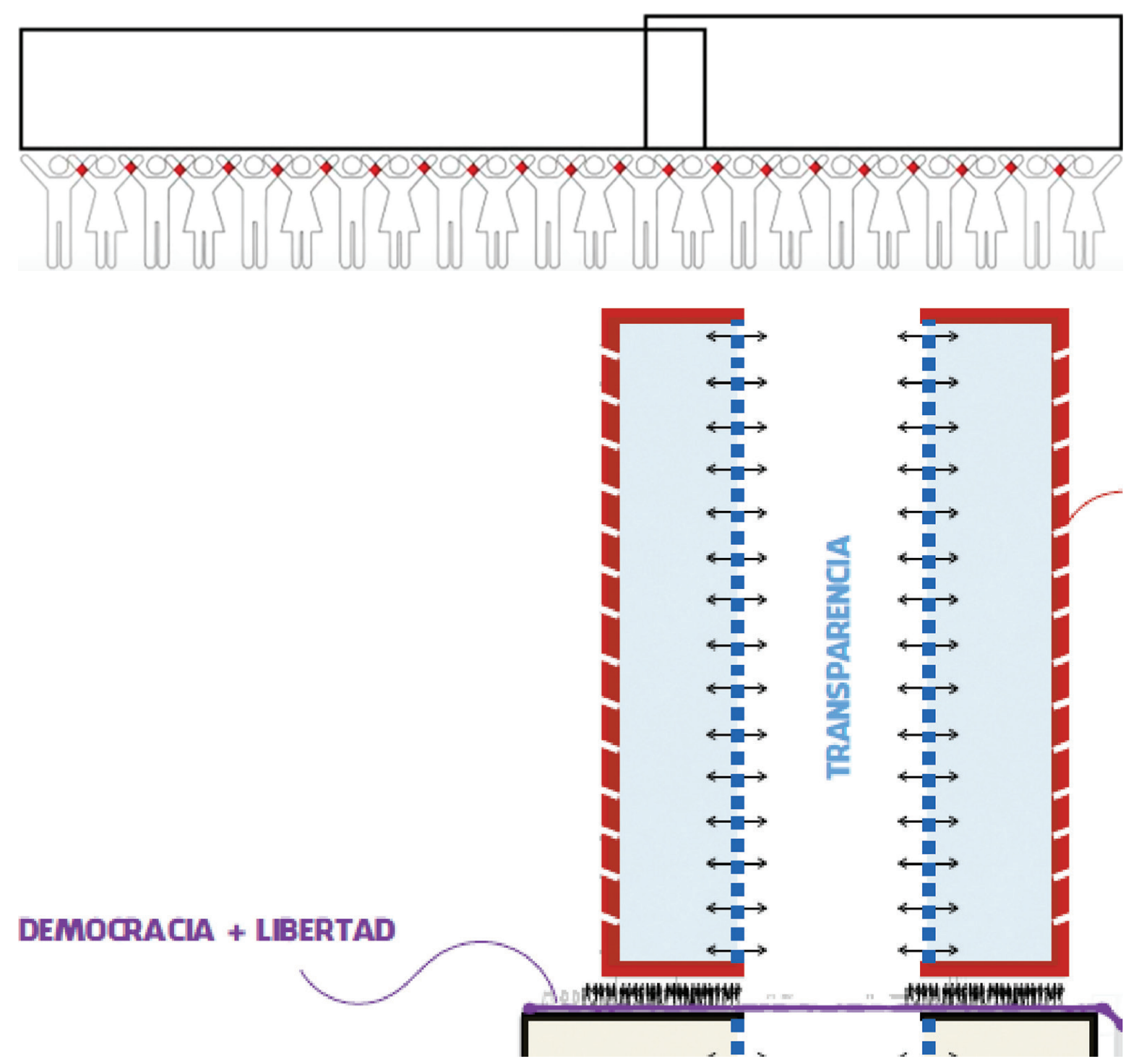
El punto en común de las representaciones arquitectónicas que adquieren estos cinco valores expuestos, así como la lectura que hace de ellos el jurado con el primer proyecto (como "máxima autoridad técnica"), es precisamente que se disputan en el plano de lo simbólico. No es de extrañar el rumbo que tomó el subsiguiente debate, donde se esgrimen diferentes significados entre opositores y promotores. Esto sucedió tanto con el proyecto "El Puente", que devino en su eventual fracaso, así como con la nueva obra y todas las connotaciones (simbólicas) que ha adquirido su propuesta en lo "conceptual", ya sean las acá expuestas ${ }^{29}$ o las que se suelen escuchar comúnmente desde los marcos interpretativos de particulares para aludir al edificio.

Asumir las características técnicas y políticas desde una perspectiva semiótica, es, desde Yaneva (2012), una de las perspectivas más convencionales del espectro teórico arquitectónico. Ya sea desde el lenguaje de signos o desde los símbolos "escondidos detrás del edificio", ambos derivan en que el sustrato material y las decisiones técnicas de los artefactos arquitectónicos se conciban como elementos estáticos, los cuales están solo para ser interpretados por "poderosos sujetos perceptivos" para explicar su significado. Este, será un sesgo inherente a la constitución del proyecto en cuestión con diversas consecuencias respecto a la orientación política de este. En primer lugar, de acá se desprende la técnica dada como algo neutral, objetivo e incuestionable (se muestra como única vía posible para resolver un problema, al mismo tiempo que escuda otras decisiones con consecuencias políticas) y en segundo lugar, la política por su parte, se relega únicamente a la lectura e interpretación que realicen los sujetos de las connotaciones del edificio, quedando sujeto a una sobreexposición de argumentos de suma cero.

Esta lógica obviará la agencia política en términos materiales del edificio construido, no interpelando, como decíamos, a la política desde el plano simbólico (que cambia radicalmente según la significación que le imprima quien diseña un símbolo y la lectura que las personas realicen de este), sino desde cómo el edificio media, desde su propia materialidad, configuración y disposiciones espaciales, la relación entre las personas con el entorno urbano construido y la sede parlamentaria. La manera en que se representan estas valoraciones y cómo se asumen los mencionados cambios, hacen ver que estos temas van más allá de lo meramente arquitectónico, pero se expresan mediante criterios técnicos que ponen en cuestionamiento su origen, orientación e instrumentalización a intereses y fuerzas que terminan por incidir en materialización final de este edificio.

\section{Materialización y agencia en el espacio construido}

La transparencia ha sido empleada por una gran diversidad de edificios parlamentarios alrededor del globo para aludir o representar la apertura democrática. Un referente importante que propone la asociación transparencia-democracia, es la cúpula propuesta por Norman Foster en el parlamento alemán (Trillo, 2010), idea que ha sido

\section{La solidez y la transparencia.}

31 Además de la acepción empleada en este caso por el Arq. Salinas y asociados, cabe destacar el uso que emplean ejemplos recientes como la Asamblea Nacional y Parque Conmemorativo de Ouagadougou del arquitecto Diébédo Francis Kéré, o bien las Cámaras del Consejo de Johannesburgo en Sudáfrica diseñadas por Pierre Swanepoel para ayudar a consolidar una idea de democracia luego de una revolución producto de más de 30 años de lucha contra una dictadura en el primer caso, o como una desviación de la arquitectura del apartheid en el segundo (Tumubiweinee, 2017).

32 Aunque es importante también considerar que el vidrio está cargado de otras propiedades como la fragilidad, su capacidad reflectiva entre otras (Yaneva, 2012). posteriormente emulada por diversas firmas de arquitectura ${ }^{31}$. Su argumento reside en la propiedad material de la transparencia del vidrio ${ }^{32}$ al que se asocian connotaciones de accesibilidad y el potencial de estimular la participación -un componente esencial de una democracia (Yaneva, 2012)-. Tomando distancia de la simbolización a la que apelan los elementos enunciados en el capítulo anterior (solidez del sistema político costarricense y la transparencia de sus procesos), nos interesa cuestionar no lo que representan sino lo que hacen o las dinámicas que permiten, ya que en esta condición reside la política que ejerce la configuración final del inmueble.

Desde este enfoque analítico, la arquitectura del edificio construido propone que la ciudadanía observe desde el espacio público la actividad del plenario. Esta disposición, en principio cierta, en realidad instaura un velo mediático donde se ve una parte del ejercicio del poder real y probablemente tan solo la tenue superficie de la actividad legislativa. Ya sea por transmisión televisiva, vía web o desde un balcón, la observación de dicha actividad no implica necesariamente una fiscalización del ejercicio del poder real, ya sea el que sucede en público y es visible, como el de las negociaciones y apretones de manos fuera del radar y escrutinio público. En este sentido, el edificio resulta inaccesible a la población y posibilita a sus ocupantes resguardarse en los 
Figura 15. Fotografía panorámica de la circulación del edificio entre despachos desde una de las esquinas internas.

Fuente: elaboración propia. numerosos espacios ciegos que contiene el proyecto y que su "solidez" permite. Ejemplo de ello, son los ascensores privados, circulaciones entre despachos al margen interno de las pesadas paredes de concreto de la fachada e independientes del resto del área "pública" (ver figura 15), los vestíbulos detrás del plenario, así como los cafetines de las subcomisiones ${ }^{33}$.

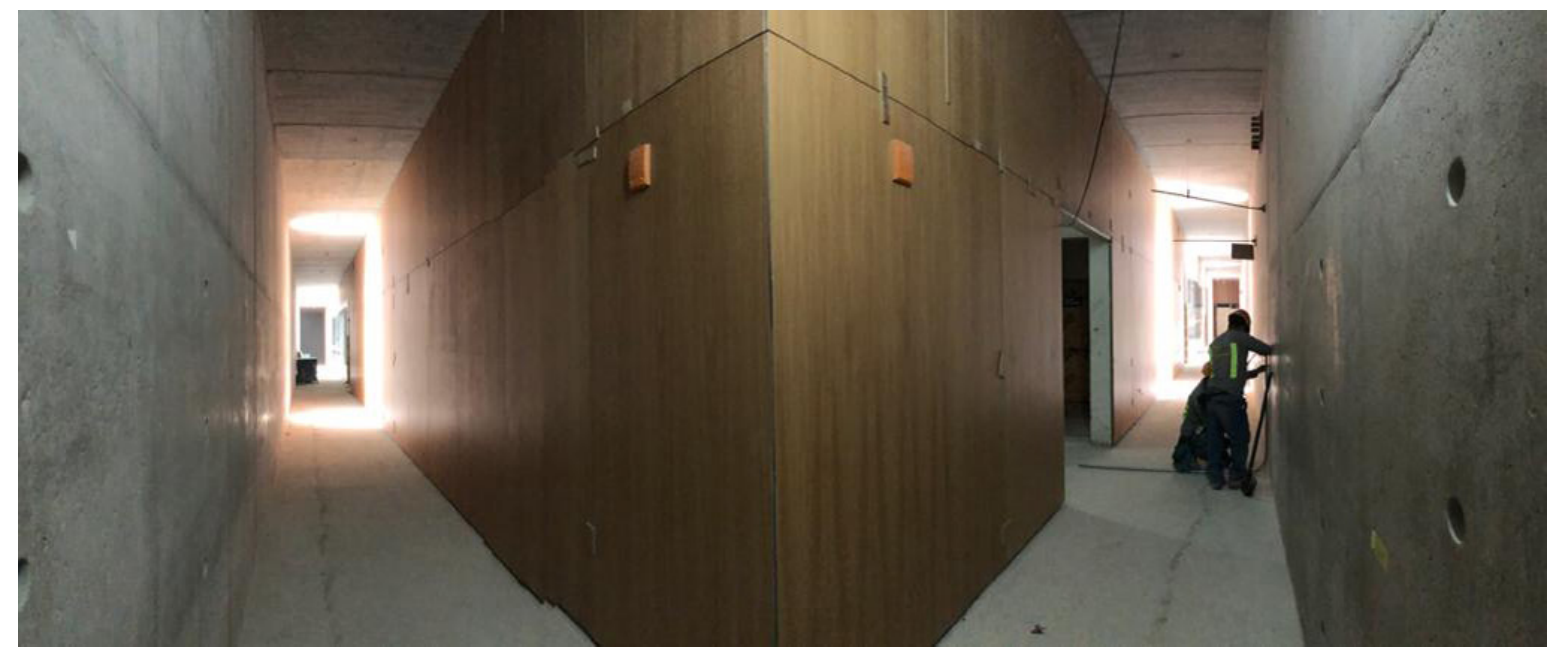

La mirada de la ciudadanía no alcanza más allá del plenario, ni más allá de unos pocos metros de los ventanales internos de las oficinas de los diputados y diputadas, por lo que la arquitectura construida poco o nada colabora a fiscalizar los procesos que afirma sustentar ${ }^{34}$. Peor aún, dichas intenciones entran en contradicción con las características que propone la solidez, por lo que estas valoraciones lejos de estar resueltas a través del diseño entran en serias inconsistencias. El oxímoron de la solidez-transparencia entendido en términos materiales, arroja los anteriores cuestionamientos sobre la accesibilidad visual del edificio, a lo que la accesibilidad física (puntos de acceso, circulaciones, obstáculos, puesto de control) aportará otro tanto para comprender la agencia política que sostiene el inmueble en relación a la ciudadanía ${ }^{35}$.

NIVEL +I (ACCESO PRINCIPAL)

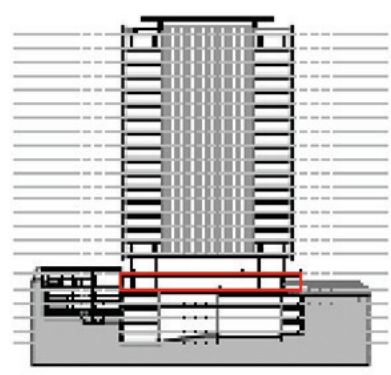

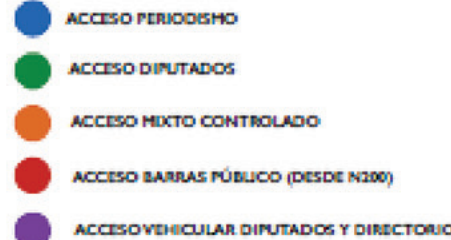

Figura 16. Axonometría del nivel urbano de la segunda propuesta en construcción. Asamblea Legislativa, s.f.

Tomado de: http://www.asamblea.go.cr/ga/ SitePages/Proyecto_Edificio_Asamblea_ Legislativa.aspx

$35 \quad$ Especialmente considerando las premisas de la firma proyectista, la cual propone que el nivel urbano resulta accesible a toda la ciudadanía y allí radica el fundamento de la representación de la "democracia costarricense".
Acá hacemos una distinción entre la accesibilidad y la posibilidad de acceso, la primera entendida como la capacidad de asegurar el libre tránsito a cualquier persona sin importar edades o condición física (y sobre la que, en efecto, hay indicios de que hubo importantes replanteos para asegurar esta cualidad y acoger la ley $7600^{36}$ (Hábitat Soluciones, 11 de agosto, 2020) y, por otro lado, la posibilidad de acceso que son las limitantes y restricciones que impone el inmueble para el ingreso y la permanencia en el espacio desde el nivel urbano.

Tal como lo muestra la figura 16, el edificio posee 5 accesos. Por el sector sur se muestra en azul el acceso periodístico, en verde el acceso a diputados y en anaranjado un acceso mixto controlado; por el costado opuesto, se muestra en morado el acceso vehicular de los diputados, diputadas y el directorio legislativo. De ese mismo lado 
36 En lo específico se cambió radicalmente el diseño de la rampa que conecta la avenida central con calle 1. En primera instancia, tal como lo muestra la imagen 16 en su esquina inferior, la rampa y las gradas estaban integradas en el diseño según la propuesta de escaleras que habían propuesto Cornelia Oberlander y Arthur Erickson en Robson Square en 1983, donde integraba por primera vez las escaleras con una rampa para asegurar la accesibilidad al lugar. Sin embargo, las vistas del edificio construido, muestran cómo se separó la rampa en un ducto independiente y se independizó de las escalinatas. Este rediseño implicó dejar algunas esquinas irresueltas. La motivación real del cambio la desconocemos, pero se podría inferir que se buscaba la seguridad de los peatones (al tropezar con las rampas mientras bajan las escaleras) y las personas con capacidades especiales para transitar de manera más segura.

Figura 17. Render del acceso principal de la segunda propuesta. Asamblea Legislativa, s.f Tomado de:http://www.asamblea.go.cr/ga/ SitePages/Proyecto_Edificio_Asamblea_ Legislativa.aspx

Figura 18. Fotografía desde la plaza urbana Norte vista hacia el atrio interno. Hábitat Soluciones, 11 de agosto, 2020.

Tomado de: https://www.youtube.com/ watch?v=FjRNnkbLZC8\&t=148s
$37 \quad$ Esta es la denominación que se emplea en Costa Rica para nombrar el sitio donde el público observa de cerca, detrás de un vidrio, la actividad del plenario. pero en un nivel superior (no mostrado en la imagen adjunta sino en otra parte de dicho documento) se muestra en rojo el acceso del público a las barras ${ }^{37}$. Un tercer sector de plaza urbana al costado este pasa tangencialmente al atrio, sin embargo, no es posible atravesar el espacio central que abre el atrio desde cualquiera de los 3 anteriores sectores, por lo que los 3 puntos de encuentro con el espacio público, no están conectados entre sí. Este atrio promueve un tipo de agencia política opuesta a la que señala Yaneva (2017) en su ejemplo. El atrio de la AL, como corazón social, no posee ninguna actividad programática más allá de unas cuantas bancas a las que solo es posible acceder una vez pasados los controles de seguridad. Incluso, podríamos afirmar, limita por completo esa oportunidad debido a que entra en conflicto con el ducto de ventilación e iluminación, también por el deliberado control que plantean los accesos y las circulaciones alrededor y hacia dentro del edificio. De ello son testigo las múltiples escalinatas, paredes hacia el espacio público, rampas y plazas elevadas, así como la reducción de la monumental entrada principal a estrechos accesos "por goteo" (ver figuras 16 y 17), los diversos puestos de control justo a la entrada del atrio (ver figura 18) y los mecanismos para garantizar "la seguridad" del edificio.
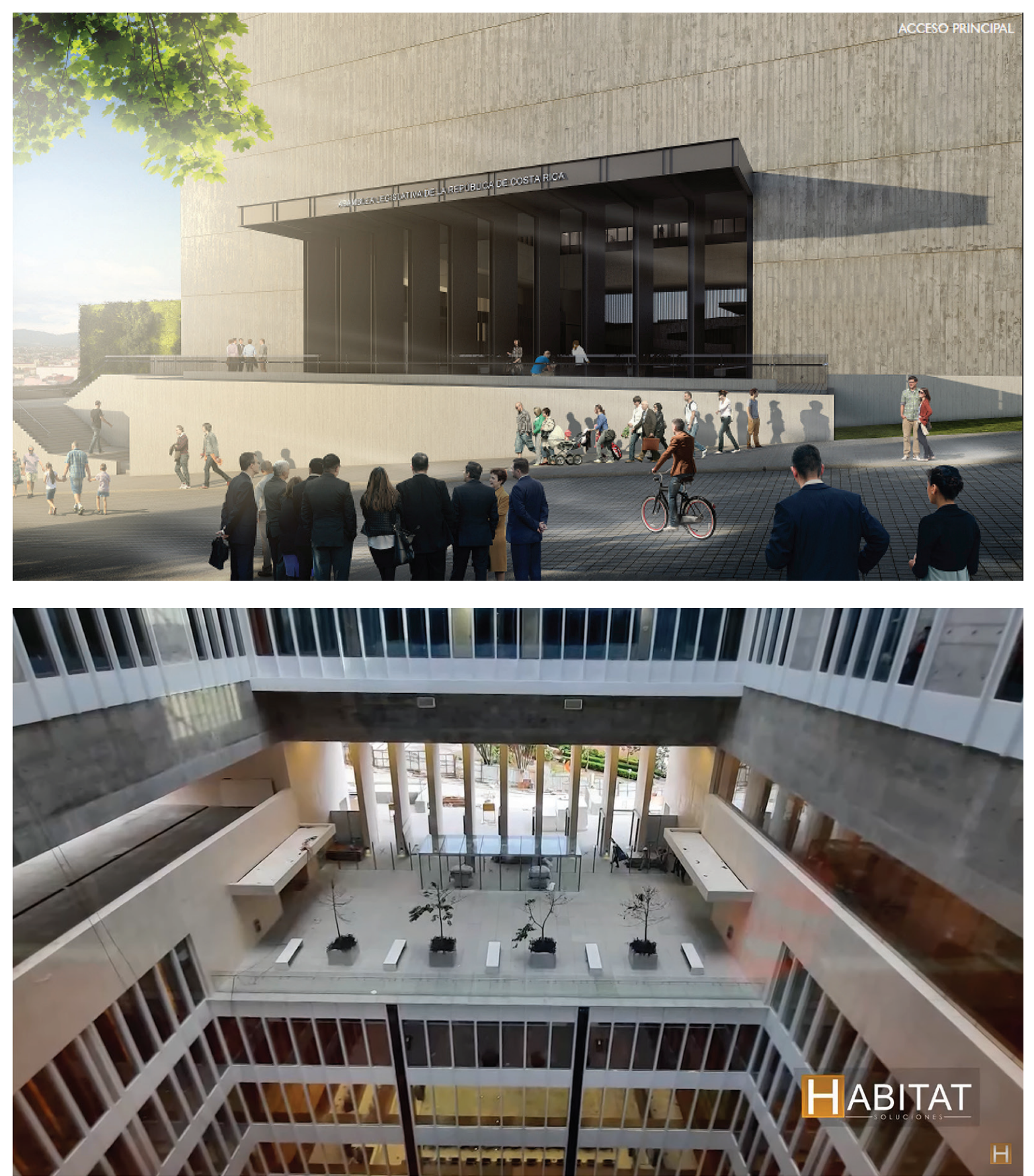

En la figura 18, es posible apreciar dicha fragmentación programática y división espacial entre el atrio del edificio y las circulaciones del nivel urbano (Parque Nacional, Plaza de la Democracia y calle 15). La cualidad del ducto de ventilación e iluminación que se fuga hacia el subsuelo, se interrumpe solo por una explanada semi-privada de la que pueden hacer uso únicamente las personas que acceden por la entrada de periodistas, diputados o "mixto controlado" (la entrada principal) y que conecta con los espacios internos a ambos lados (hacia la derecha el salón de expresidentes y hacia la izquierda hacia la recepción). En el margen izquierdo se observa otra plaza a nivel público que "se asoma" al atrio pero que tampoco conecta con ningún otro espacio. El atrio como "corazón" del edificio, lejos de fomentar el encuentro e incentivar la participación en el edificio, deslinda estratégicamente los diferentes sectores del nivel urbano, dejando entredicho la "libertad" que se pregona discursivamente (y que se abordaba en el capítulo anterior). 
38 Representadas originalmente por unas vigas de metal verticales y posteriormente reemplazadas por esferas precolombinas y unas cuantas bancas en el proyecto finalmente construido.

$39 \quad$ Otro claro ejemplo de ello, aunque aún no pudimos corroborar su funcionamiento, son los mecanismos de inundación de las plazas públicas que yacen bajo la infraestructura y se encuentran por así decirlo "techadas", las cuales se inundan por la noche para ahuyentar a las personas habitantes de calle que podrían pernoctar en estos espacios del edificio.

40 Algo similar, explica Winner (2008), ocurre con un decreto legislativo, el cual estructura un marco de orden público al aportar nuevos criterios sobre poder y autoridad, de igual manera, los artefactos socio-técnicos, van a trabajar de la misma manera al sentar un orden espacial que permite realizar, o no, ciertas actividades. Sin embargo, todos sabemos que, al igual que la ley, ésta a veces se quebranta, se cuestiona o incluso llega a cambiarse.

41 Entiéndase, dentro de otros perjuicios, el golpe que ha significado al paisaje josefino el deslinde del contexto urbano a quienes se encuentran por fuera de la vida política institucional, que en su interior desborda comodidades, extremo confort y lujo, por mencionar lo menos de un edificio pensado para "eficientizar" al máximo (y con todas sus implicaciones y asociaciones) el quehacer legislativo.
Extendiendo más allá la lectura de la condición de acceso (y retomando la última de las palabras que conforman el concepto del edificio), cabe destacar que los espacios más relevantes propuestos por sus diseñadores desde el plano, son, en el extremo inferior las raíces ${ }^{38}$ y en el extremo superior del edificio la naturaleza (Asamblea Legislativa de Costa Rica, 2019; Hábitat Soluciones, 2020), ambos, se encuentran a disposición de la administración para determinar si van a ser o no accesibles a la ciudadanía. Estos se yerguen como símbolos dispuestos por el diseñador para ser acogidos, y, a lo sumo, admirados desde la lejanía por el público.

Sin embargo, la condición futura de estos espacios, y su utilización por la ciudadanía, resulta aún incierta dadas las inherentes restricciones espaciales de acceso vertical intrínsecas a la propuesta arquitectónica y que estará por resolverse con su apertura oficial. Por estas diversas restricciones (ya sean propias del objeto construido o por disposición de la administración), la condición de acceso resulta exactamente eso: una condición, pautada y calibrada, para ceder espacios sin perder ningún control sobre la sede. Si bien el aporte de una plaza pública al norte del edificio y las amplias circulaciones en torno al edificio compensan en alguna medida la instauración del inmueble en el espacio urbano, urbano, las anteriores limitaciones hacen que la configuración del edificio, por su agencia material, vaya a contrapelo de la propuesta que se pretendía realizar (libertad y democracia) ${ }^{39}$.

Cabe señalar que lejos de caer en un determinismo arquitectónico donde el edificio impone ciertas acciones y alienta algunos comportamientos sobre otros (Yaneva, 2017), la agencia política se da a partir de lo que anunciábamos como disposiciones espaciales, en el entendido de que hay una relación activa entre los objetos dispuestos a hacer algo y las personas, quienes abren un margen de aceptación o de cambio hacia estas ${ }^{40}$. Por lo que el edificio presenta una serie de espacios abiertos a ser reinterpretados a futuro en tanto los usos que propone y funciones que delimitan. Las diversas disposiciones materiales aquí expuestas se pueden asumir como parte de las diferentes tecnologías que terminan por componer el artefacto socio-técnico que resulta en suma el nuevo edificio legislativo.

Desde este sustrato material, es posible apreciar cómo la técnica no es algo objetivo, neutral e inamovible, por el contrario, como lo menciona Winner (2008) las tecnologías tienen la capacidad de incrementar el poder, la autoridad y el privilegio de unos grupos sociales sobre otros. Incluso, el capítulo evidencia como "un artefacto dado podría haber sido diseñado y construido de manera tal que produzca una serie de consecuencias lógica y temporalmente previstas a cualquiera de sus usos declarados." (Winner, 2008, p. 31). De acá se desprende que la arquitectura del proyecto y su entorno urbano, lejos de ser herramientas imparciales, se presenten como artefactos inherentemente políticos, resultado de un proceso de disputa contingente, dirigido por intereses que van más allá del deseo de innovación, una mera conceptualización artístico-arquitectónica o la satisfacción de una necesidad. Puesto que el edificio, en su condición de artefacto técnico inscribe y expresa las nociones enunciadas de su contexto, de las cuales luego se deslinda pero que igualmente ejerce en sus interacciones materiales, termina por reflejar claramente las estructuras que lo soportan. Al mismo tiempo que distribuye de manera desigual los beneficios de las pérdidas ${ }^{41}$ sobre la parte de la ciudadanía que entrará en relación directa o indirecta con este artefacto.

\section{Conclusiones}

El proceso para satisfacer la necesidad de una nueva sede legislativa, brindó un esbozo sobre la democracia en acto, el papel de la "técnica", en el marco de discusiones sociopolíticas amplias y la forma en que un criterio busca imponerse recurriendo a los medios disponibles para llevarlo a cabo. La ligereza con que se construye y muta un discurso arquitectónico, e incluso la carencia de compromiso consigo mismo al contradecirse de manera vehemente. Lo vaga -y abierta a la interpretación- que puede ser una ley y la forma en que una institución estatal se posiciona según quién sea el jerarca que la preside. Estos elementos, posteriormente, se concretaron en una edificación que los representa material y metafóricamente, al ser una construcción vertical con dualidades 
muy marcadas: cerrada hacia afuera con gruesos muros de hormigón y abierta con vidrio hacia adentro, opaca al exterior y traslucida al interior; con una disposición espacial que refleja y tiende al desencuentro y al ocultamiento, manifiesto tanto en el atrio, como en el acceso y la ubicación del plenario a tres pisos bajo tierra. Estas disposiciones espaciales devienen en posturas políticas, por la condición de posibilidad para el hacer futuro que encarnan. Con lo cual, no se apunta a una afirmación arquitectónica determinista, puesto que las agencias de actores individuales y colectivos no quedan suprimidas, sino a la condicionalidad material, intencionada o no, y lo que puede generar.

La excepcionalidad que supuso la realización de un concurso público de diseño, se vio opacada por la forma en que este se desarrolló. En ese sentido, fue contraproducente, en relación con el fin particular del concurso y marca un precedente negativo para la apertura de espacios de este tipo. Irónicamente, el hecho de que el jurado buscara un "edificio ícono" únicamente desde el plano simbólico, devino en el principal obstáculo para obtener el permiso del CICPC y, en alguna medida, que finalmente se tramitara una solución arquitectónica de puerta cerrada: sin debate de pares y parecida, en su tipología vertical, a las que fueron descalificadas en el marco de un concurso. Lo anterior puso en entredicho a la forma en que se toman decisiones de competencia arquitectónicas, pero también al CFIA, quién tuvo participación directa en dos momentos: la designación del jurado y la elaboración de un análisis técnico ampliamente cuestionado por su ligereza, superficialidad y parcialización a favor del proyecto sin lograr resolver el fondo de la disputa.

Es claro que la AL tenía urgencia funcional de una nueva sede y por ello suscribe el fideicomiso con el BCR como la forma de justificar financieramente el proyecto "sin aporte de capital" y "adquisición de deuda". A partir de ese momento, el fideicomiso se convierte en un "buen vecino con un gran garrote" que tutela y vigila el marco posible de acciones, aunque las decisiones finales competan formalmente al Directorio Legislativo de turno, en tanto que fideicomitente y fideicomisario. Quizá el ejemplo más claro de esto fue la decisión precipitada de anunciar al ganador del concurso, a pesar de las reservas y el criterio negativo del CICPC. Pero también al flexibilizar los criterios en favor del proyecto que el jurado del concurso consideraba excepcional e icónico. Esta confluencia de factores hizo pasar el proceso por un camino infructuoso de acusaciones, demandas, denuncias y conflictos institucionales contraproducentes para los intereses de la AL.

A raíz de esto, surge una serie de interrogantes. Si la verticalidad no es democracia, ¿por qué se impuso la figura del fideicomiso como la única solución financiera posible a pesar de su costo e implicaciones?, ¿por qué se le dio un tratamiento especial a un anteproyecto que no cumplía con las condiciones del concurso?, ¿por qué la AL siguió adelante con un proyecto inviable si ya tenía conocimiento de esta situación y por qué se quiso imponer autoritariamente al criterio del CICPC?, ¿por qué los criterios de una y otra parte se calificaron como subjetivos y arbitrarios?, ¿por qué se llegó a un acuerdo con el mismo consultor y no se hizo otro concurso público? y ¿por qué es tan necesario un "edificio ícono" si lo que importa es la solidez en acto del sistema político?.

Quizá sea porque más allá de la ligereza de la metáfora hay verdad en la siguiente afirmación: la verticalidad no es democracia y el proceso de gestación del edificio es una prueba de ello. Con lo cual, lo faraónico del inmueble y la necesidad de un ícono representativo, se convierten en un signo vehemente de la debilidad estructural de la democracia actual costarricense y su falsedad. Lo cual plantea un problema serio y profundo, especialmente en el cierre de una década convulsa y en la antesala del bicentenario de la Independencia.

\section{Referencias bibliográficas}

Bonjour, L. (2002) Internalism and externalism. En Moser, P. (Ed.) (2002) The Oxford Handbook of Epistemology. Oxford, Inglaterra: Oxford University Press.

Caro, R. (1975) The power broker. The fall of New York. Robert Moses and the fall of New York. USA: Vintage Books. 
Jiménez, A. (2008) El imposible país de los filósofos. San José, Costa Rica: Editorial UCR.

Molina, I. (2005) Costarricense por dicha. Identidad nacional y cambio cultural en Costa Rica durante los siglos XIX y XX. San José, Costa Rica: Editorial UCR.

Mora, C. (2019) El Castillo Azul. Ícono de un cambio de era. San José, Costa Rica: IFED-TSE. Obtenido desde: https://www.tse.go.cr/pdf/publicaciones/el-castilloazul.pdf

Pinch, T. (1997) La construcción social de la tecnología: Una revisión. En Santos, M. y Díaz, R. (Coord.) Innovación tecnológica y procesos sociales: Perspectivas teóricas. México DF, México: Fondo de cultura económica.

Pinch, T. y Bijker, W. (2013) La construcción social de hechos y artefactos: 0 acerca de cómo la sociología de la ciencia y la sociología de la tecnología pueden beneficiarse mutuamente. En Thomas, H. \& Buch, A. (Coord.) Actos, actores y artefactos. Sociología de la tecnología. Buenos Aires, Argentina: Universidad Nacional de Quilmes.

Pinch, T. y Trocco, F. (2004) Analog days: The invention and impact of Moog synthesizer. USA: Harvard University Press.

Trillo, M. (2010). A la luz de las cúpulas. Restauración del Reichstag de Berlín (19921999). Foster \& Partners. Revista Proyecto, Progreso, Arquitectura, s.v.(2), 83-95. Obtenido desde: https://revistascientificas.us.es/index.php/ppa/article/view/15/25

Tumubiweinee, P. (15 de junio, 2017). Governments in glass houses... transparency and the african government. Recuperado de: https://momothemagazine.com/ african-government/

Winner, L. (2008) ¿Tienen política los artefactos? La ballena y el reactor. Una búsqueda de los límites en la era de la alta tecnología. Barcelona, España: Gedisa.

Yaneva, A. (2012) Mapping Controversies in Architecture. Great Britain: MPG Books Group.

Yaneva, A. (2017). Five Ways to Make Architecture Political: An Introduction to the Politics of Design Practice. Great Britain: Bloomsbury Academic.

Yurica, K. (Abril, 2013) Propuestas de anteproyectos para el nuevo edificio de la Asamblea Legislativa. Habitar. Edición 80. 48-89. Obtenido desde: https://issuu. com/arquitectoscr/docs/habitar80digital

\section{Documentos y recursos web institucionales}

Asamblea Legislativa (s.f.) Financiamiento y recursos. Obtenido desde: http://www. asamblea.go.cr/ga/SitePages/Financiamiento_Recursos.aspx

Asamblea Legislativa (s.f.) Razones para un nuevo edificio. Obtenido desde: http:// www.asamblea.go.cr/ga/SitePages/Razones_Para_Nuevo_Edificio.aspx

Asamblea Legislativa (s.f.) Sobre edificios patrimoniales. Obtenido desde: http://www. asamblea.go.cr/ga/SitePages/Preguntas_Edificios_Patrimoniales.aspx.

Asamblea Legislativa de Costa Rica (s.f.). Proyecto Nuevo Edificio de la Asamblea Legislativa. Obtenido desde: http://www.asamblea.go.cr/ga/SitePages/Proyecto_ Edificio_Asamblea_Legislativa.aspx

Asamblea Legislativa de Costa Rica (Productor). (2019). Nuevo Edificio Legislativo entra en etapa final. [Video YouTube]. Obtenido desde: https://www.youtube.com/ watch?v=ahdeAPFefcQ

Asamblea Legislativa/Banco de Costa Rica. (25 de enero, 2012). Fideicomiso inmobiliario Asamblea Legislativa/BCR 2011. / Adendum número 1 al Contrario Fideicomiso Refrendado [Documento oficial del Fideicomiso AL/BCR]. Obtenido desde: http:// www.asamblea.go.cr/ga/Proyectos\%20Sede\%20Legislativa/3-Fideicomiso/ Documentos $\% 20 \mathrm{de} \% 20$ consulta/Contratos/CONTRATO $\% 20$ DE $\% 20$ FIDEICOMISO\%20ASAMBLEA\%20LEGISLATIVA\%20Y\%20ADENDUM\%20 $\mathrm{N} \% \mathrm{C} 2 \% \mathrm{BA} 1 . \mathrm{pdf}$ 
Centro de Investigación y Conservación del Patrimonio Cultural (04 de marzo, 2015) Circular $N^{\circ}$ CPC-0308-2015. Obtenido desde: http://www.icomoscr.org/doc/ asamblea/OFICIAL_(2015-03-04)Circular-archivo-proyecto-CPC-0308-2015.pdf

Centro de investigación y Conservación del Patrimonio Cultural (20 de septiembre, 2016). Resolución Na. CPC-1473-2016. Obtenido desde: http://www.icomoscr. org/doc/asamblea/CPC_(2016-09-20)AvalCentroPatrimonio-NuevaAsamblea.pdf

Colegio Federado de Ingenieros y Arquitectos (Junio, 2014) Análisis técnico. Nuevo Edificio de la Asamblea Legislativa. Según Fideicomiso de laAsamblea Legislativa/ $B C R$ 2011. Obtenido desde: http://www.icomoscr.org/doc/asamblea/[FAVOR] CFIA_(2014-06-24)Analisis-tecnico-nuevo-edificio-asamblea-legislativa.pdf

Directorio Legislativo, Asamblea Legislativa (30 de enero, 2013) Reunión del Directorio Legislativo. Sesión extraordinaria No155-2013. Obtenido desde: http://www. asamblea.go.cr/glcp/Documentos\%20compartidos/Acta155-2013.pdf

Directorio Legislativo, Asamblea Legislativa (24 de marzo, 2015) Reunión del Directorio Legislativo. Sesión extraordinaria No50-2015. Obtenido desde: http://www. asamblea.go.cr/glcp/Documentos\%20compartidos/ACTA050-2015\%20PORTAL. pdf

Directorio Legislativo, Asamblea Legislativa (27 de abril, 2015) Reunión del Directorio Legislativo. Sesión extraordinaria $N^{\circ}$ 57-2015. Obtenido desde: http://www. asamblea.go.cr/glcp/Documentos\%20compartidos/ACTA057-2015\%20PORTAL. pdf

Directorio Legislativo, Asamblea Legislativa (29 de noviembre, 2016) Reunión del Directorio Legislativo. Sesión ordinaria N`146-2016. Obtenido desde: http://www. asamblea.go.cr/glcp/Documentos\%20compartidos/ACTA146-2016\%20PORTAL. pdf

Escuela de Arquitectura (12 de septiembre, 2016) Declaración de la Asamblea Ampliada de la Escuela de Arquitectura de la Universidad de Costa Rica, ante el proyecto para la construcción del nuevo conjunto edilicio de la Asamblea Legislativa de Costa Rica. Obtenido desde: https://www.ucr.ac.cr/medios/documentos/2016/ pronunciamiento-arquis-ucr.pdf

Granados, V. (s.f.) Directorio Legislativo. Informe de Labores periodo 1 de mayo de 2012 a 30 de abril 2013. Obtenido desde: http://www.asamblea.go.cr/glcp/Rend_ direc/Informe\%20Diputado\%20Victor\%20Emilio\%20Granados\%20Calvo.pdf

Laborda, C. (Julio, 2014) Observaciones y consideraciones sobre el análisis técnico del nuevo edificio Asamblea Legislativa realizado por el CFIA. Obtenido desde: http://www.icomoscr.org/doc/asamblea/ESPECIALISTA_(2014-07-10)ARQ. CarlosLaborda-contra-informe-CFIA.pdf

Ley de Presupuesto ordinario y extraordinario de la República para el Ejercicio económico 2012. Ley $n^{\circ} 9019$ (2011). Obtenido desde: https://www.hacienda. go.cr/docs/51d1a11d76433_Ley2012_tit_101.pdf

Ley de Presupuesto ordinario y extraordinario de la República para el Ejercicio económico 2013. Ley nº 9103 (2012). Obtenido desde: https://www.hacienda. go.cr/docs/51daf4ff2b30f_ProyLey2013_Tit101.pdf

Ley de Presupuesto ordinario y extraordinario de la República para el Ejercicio económico 2014 Ley $n^{\circ} 9193$ (2013). Obtenido desde: https://www.hacienda. go.cr/docs/529f428d98f5e_Ley2014_TIt101.pdf

Ley de Presupuesto ordinario y extraordinario de la República para el Ejercicio económico 2015. Ley n` 9289 (2014). Publicada en Diario Oficial La Gaceta N²41 (Tomo VIII) del 15 de diciembre. San José, Costa Rica: Imprenta Nacional. Obtenido desde: https://www.imprentanacional.go.cr/pub/2014/12/15/ALCA80H_15_12_2014.pdf

Ley de Presupuesto ordinario y extraordinario de la República para el Ejercicio económico 2016. Ley $n^{\circ} 9341$ (2015). Publicada en Diario Oficial La Gaceta N 240 (Tomo V) del 10 de diciembre. San José, Costa Rica: Imprenta Nacional. Obtenido desde: https://www.imprentanacional.go.cr/pub/2015/12/10/ALCA112E_10_12_2015.pdf 
Ley de Presupuesto ordinario y extraordinario de la República para el Ejercicio económico 2017. Ley $n^{\circ} 9411$ (2016). Publicada en Diario Oficial La Gaceta $\mathrm{N}^{\circ} 299 \mathrm{C}$ (Tomo III) del 12 de diciembre, 2016. San José, Costa Rica: Imprenta Nacional. Obtenido desde: https://www.imprentanacional.go.cr/pub/2016/12/12/ ALCA299C_12_12_2016.pdf

Ley de Presupuesto ordinario y extraordinario de la República para el Ejercicio económico 2018. Ley $n^{\circ} 9514$ (2017). Publicada en Diario Oficial La Gaceta Nº 301 (Tomo XVI) del 14 de diciembre. San José, Costa Rica: Imprenta Nacional. Obtenido desde: https://www.imprentanacional.go.cr/pub/2017/12/14/ALCA301P_14_12_2017.pdf

Ley de Presupuesto ordinario y extraordinario de la República para el Ejercicio económico 2019. Ley $n^{\circ} 9632$ (2018). Publicada en Diario Oficial La Gaceta Nº 207 (Tomo V) del 11 de diciembre. San José, Costa Rica: Imprenta Nacional. Obtenido desde: https://www.imprentanacional.go.cr/pub/2018/12/11/ALCA207E_11_12_2018.pdf

Ley de Presupuesto ordinario y extraordinario de la República para el Ejercicio económico 2020. Ley n`9791 (2019). Publicada en Diario Oficial La Gaceta Nº 233 (Tomo II) del 6 de diciembre. San José, Costa Rica: Imprenta Nacional. Obtenido desde: https://www.imprentanacional.go.cr/pub/2019/12/06/ALCA273B_06_12_2019.pdf

Ley de Presupuesto Ordinario y Extraordinario para el Ejercicio Económico 2021. Proyecto $n^{\circ} 22.174$ (2020) Publicado en Diario Oficial La Gaceta. Obtenido desde: https://www.imprentanacional.go.cr/pub/2020/09/18/ALCA245C_18_09_2020.pdf

Ministerio de Cultura y Juventud, Despacho del Ministro (1 de marzo, 2014) Resolución NDM-50-2014. Obtenido desde: http://www.icomoscr.org/doc/asamblea/MCJ_ (2014-03-31)Rechazo-apelacion-y-apoyo-CICPC.pdf

Ministerio de Cultura y Juventud, Despacho de la Ministra (1 de agosto, 2014) Resolución Administrativa $N^{\circ} D M-223-2014$. Obtenido desde: http://www.icomoscr.org/doc/ asamblea/MCJ_(2014-08-01)Rechazo-apelacion-fideicomisoBCR.pdf

Ministerio de Cultura y Juventud, Despacho de la Ministra (4 de agosto, 2016) Resolución $N^{\circ} D M-177-2016$. Obtenido desde: http://www.icomoscr.org/doc/asamblea/MCJ_ (2016-08-04)Rechazo-apelacion-ICOMOS.pdf

Prensa, audiovisuales y blogs

Alfaro, J. (7 de marzo, 2018) 60 años después inicia la construcción del nuevo edificio legislativo. Semanario Universidad. Nacionales. Obtenido desde: https:// semanariouniversidad.com/pais/60-anos-despues-inicia-la-construccion-delnuevo-edificio-legislativo/

Asamblea Legislativa de Costa Rica (Productor). (7 de octubre, 2019). Nuevo Edificio Legislativo entra en etapa final. [Video YouTube]. Obtenido desde: https://www. youtube.com/watch?v=ahdeAPFefcQ

Astorga, L. (11 de septiembre, 2019) Tras la mudanza a su nueva casa, ¿qué pasará con los edificios antiguos de la Asamblea Legislativa? La Nación. Patrimonio. Obtenido desde: https://www.nacion.com/el-pais/patrimonio/tras-la-mudanza-asu-nueva-casa-que-pasara-con/NOTNETWKYJCH3MPFCHNASCTE6Q/story/

Chavarría, D. (28 de mayo, 2014) Nueva sede de Asamblea Legislativa lucha para no sucumbir. Semanario Universidad. Obtenido desde: https://historico. semanariouniversidad.com/sin-categoria/nueva-sede-de-asamblea-legislativalucha-para-no-sucumbir/

Diario Extra (04 de junio, 2014) Sindicato denuncia manosea familiar. Diario Extra. Nacionales. Obtenido desde: https://www.diarioextra.com/Noticia/detalle/233195/ sindicato-denuncia-manoseo-familiar

Granados, G. (1 de febrero, 2019) Edificio legislativo será ф17 000 millones más caro. Atribuyen aumento a tipo de cambio y huelga. Diario extra. Nacionales. Obtenido desde: https://www.diarioextra.com/Noticia/detalle/381139/edificio-legislativosera-\%C2\%A217000-mills-mas-caro 
Hábitat Soluciones (11 de agosto, 2020) Edificio nuevo Asamblea Legislativa 2020 [video de YouTube]. Obtenido desde: https://www.youtube.com/ watch?v=FjRNnkbLZC8\&ab_channel=H\%C3\%A1bitatSoluciones

Herrera, C. (29 de septiembre, 2019) ¿No le gusta la nueva Asamblea Legislativa? Descubraentonceslasjoyasarquitectónicas delosedificios delCongreso.LaNación. Revista Dominical. Obtenido desde: https://www.nacion.com/revista-dominical/nole-gusta-la-nueva-asamblea-legislativa/PFSSKBWUHZFQFIEPFWCI4QXADI/ storyl

Hidalgo, E. (14 de octubre, 2019) Entendiendo el concurso que eligió el edificio de la Asamblea Legislativa. aDiariocr.com. Cultura. Obtenido desde: https://adiariocr. com/cultura/conozca-los-disenos-que-no-Ilegaron-a-ser-la-asamblea-legislativa/

La Nación (21 de mayo, 2013) Criterio técnico en el desarrollo de infraestructura. La Nación. Foros. Obtenido desde: https://www.nacion.com/opinion/foros/criteriotecnico-en-el-desarrollo-de-infraestructura/74RIJ4IMYRE2TNG6FCVLT4VOKU/ storyl

La Nación (3 de mayo, 2015) El Castillo Azul: una histórica mansión en cuesta de Moras. La Nación. Cultura. Obtenido desde: https://www.nacion.com/ viva/cultura/el-castillo-azul-una-historica-mansion-en-cuesta-de-moras/ ZMXXHTTSUZHGHKR5QJVGUKCZ5Q/story/

La República (Productor). (2013). Diseño del Nuevo edificio de la Asamblea Legislativa [Video YouTube]. Obtenido desde: https://www.youtube.com/watch?v=MoMPfW5EKo

Monge, L. (12 de setiembre 2019) Entrevista realizada al Arq. Luis Alberto Monge. Recuperado de: https://monarqui.blogspot.com/2020/03/entrevista-sobre-eledificio-de-la.html

Ramírez, A. (1 de noviembre, 2016) Arquitecto ofrece devolver "en pagos de polaco" \$25 mil mensuales al Congreso. CRHoy. Nacionales. Obtenido desde: https:// www.crhoy.com/nacionales/arquitecto-ofrece-devolver-en-pagos-de-polaco-25mil-mensuales-al-congreso/

Ruíz, P. (19 de septiembre, 2020) En un mes exacto los diputados estrenarán edificio de $\$ 82.500$ millones. El Observador. Obtenido desde: https://observador.cr/enun-mes-exacto-los-diputados-estrenaran-edificio-de-\%c2\%a282-500-millones/

Salazar, A. (7 de febrero, 2013). Proyecto Mora - Una lección de Arquitectura y democracia. [Entrada en Blog]. Obtenido desde: https://alephcr.wordpress. com/2013/02/07/proyecto-mora-una-leccion-de-arquitectura-y-democracia/

Soto, J. (5 de marzo, 2015) Congreso renunciará a diseño de puente para el nuevo edificio legislativo. CRHoy. Política. Obtenido desde: https://archivo.crhoy.com/ congreso-renunciara-a-diseno-de-puente-para-el-nuevo-edificio-legislativo/ nacionales/

Valverde, L. (8 de octubre, 2019) Primer año de nuevo edificio legislativo significará $\phi 12$ mil millones más en presupuesto. CRHoy. Política. Obtenido desde: https:// www.crhoy.com/nacionales/primer-ano-del-nuevo-edificio-legislativo-significara\%E2\%82\%A112-mil-millones-mas-en-presupuesto/

\section{Cartas}

Monge, G. (19 de febrero del 2014) [Carta para el Ing. Olman Vargas, Presidente Ejecutivo del CFIA]. Obtenido desde: https://www.crhoy.com/wp-content/ uploads/2014/10/01-Olman-Vargas-2014-02-19-1.pdf

Monge, G. (25 de junio, 2014) [Carta al Ing. Olman, Presidente Ejecutivo del CFIA]. Obtenido desde: http://www.icomoscr.org/doc/asamblea/ESPECIALISTA_(201406-25)ING.GustavoMonge-contra-informe-CFIA.pdf 


\section{Entrevistas}

Rojas, A. (Martes 4 de febrero, 2020) Comunicación personal. 